\title{
Is Positive Sentiment in Corporate Annual Reports Informative? \\ Evidence from Deep Learning
}

Mehran Azimi and Anup Agrawal*

Current draft: July 2019

Comments welcome

* Both authors: University of Alabama, Culverhouse College of Business, Tuscaloosa, AL 35487-0224. Azimi: (334) 524-3086, mazimi1@crimson.ua.edu. Agrawal: (205) 348-8970, aagrawal@cba.ua.edu. We thank Mark Chen, Doug Cook, Mike Cooper, Marco Enriquez, Jerry Hoberg, Ravi Jagannathan, Erik Johnson, Anzhela Knyazeva, Diana Knyazeva, Lei Kong, Kelvin Liu, Kevin Mullally, Sugata Ray, Ken Rosen, Andy Wu (discussant), Feng Zhang and conference and seminar participants at MFA, SEC and the University of Alabama for helpful comments. The authors acknowledge financial support from a summer research grant from the Culverhouse College of Business (Azimi) and the William A. Powell, Jr. Chair in Finance and Banking (Agrawal). All errors are our own. 


\title{
Is Positive Sentiment in Corporate Annual Reports Informative? \\ Evidence from Deep Learning
}

\begin{abstract}
We use a novel text classification approach from deep learning to more accurately measure sentiment in a large sample of 10-Ks. In contrast to most prior literature, we find that positive, and negative, sentiment predicts abnormal return and abnormal trading volume around $10-\mathrm{K}$ filing date and future firm fundamentals and policies. Our results suggest that the qualitative information contained in corporate annual reports is richer than previously found. Both positive and negative sentiments are informative when measured accurately, but they do not have symmetric implications, suggesting that a net sentiment measure advocated by prior studies would be less informative.
\end{abstract}

Keywords: Corporate annual reports, $10-\mathrm{K}$ filings, Textual analysis, Textual sentiment classification, Deep learning

JEL classification: C81, D83, G10, G14, G30, M41 


\section{Is Positive Sentiment in Corporate Annual Reports Informative?}

\section{Evidence from Deep Learning}

\section{Introduction}

Public companies report qualitative information along with quantitative information about their operations and performance in annual reports filed with the SEC as Form 10-K. Whether the text of these $10-\mathrm{K}$ filings contains information beyond the quantitative information in the filing, and whether the market reacts to that information are unsettled empirical questions for at least two reasons. First, measuring positive sentiment is challenging and the evidence on its information content is scarce. One challenge is that measures of positive sentiment tend to be ambiguous in the business context, where positive words are often used to convey negative information, as Loughran and McDonald (2016) point out in a comprehensive review article on textual analysis in finance and accounting. Second, recent developments in natural language processing (NLP) make it necessary to re-evaluate previous findings (see, e.g., Loughran and McDonald (2016)). Compared to methods that have been used for more than two decades, new sentiment classification methods come closer in their approach and accuracy to intelligent agents, i.e., human beings. These new methods allow us to learn where prior methods are appropriate and efficient, and where there is potential for improvement. In addition, the use of state-of-the-art sentiment classification techniques is becoming widespread in the investment industry, yet there is limited systematic evidence on their value.

Sentiment ${ }^{1}$ analysis in finance has focused mainly on two methods: word-based methods and sentence-based Naïve Bayes classification (NBC) method. Researchers using word-based methods develop context-specific word lists and sometimes apply term-weighting schemes ${ }^{2}$ to

${ }^{1}$ We follow the literature and use the term 'sentiment' to refer to both views or opinions and facts based on fundamentals because the two are intertwined and hard to disentangle.

${ }^{2}$ In an equal-weighting scheme, all the words are viewed as equally important and the tone of a text is the sum of the number of all the words in a specific word list divided by the total number 
improve the quality of sentiment measures. Gentzkow, Kelly and Taddy (2019) point out that while word-based methods are appropriate in some settings, these methods don't consider words in the context of sentences. $\mathrm{NBC}^{3}$ methods address this issue to some extent, but still cannot achieve a high degree of accuracy due to several inherent limitations of this approach, as discussed in section 2. Borrowing from the natural language processing (NLP) and deep learning disciplines (see, e.g., Mikolov et al. (2013a), Mikolov et al. (2013b), Hochreiter and Schmidhuber (1997), and Wang et al. (2015)), we use a novel text classification method to measure the sentiment in $10-\mathrm{K}$ filings. We then evaluate the informativeness of these sentiment measures. Our sentence-based sentiment classifier achieves an out-of-sample accuracy of $90 \%$, which is significantly higher than the accuracy achieved in previous studies, which ranges from $45 \%$ to $77 \%$.

Our method for classifying the sentiment in a sentence consists of two steps. As in a typical classification problem, a function operates on features and provides the probability that an observation belongs to each class. In our study, an observation is a sentence and classes are positive, negative, and neutral sentiments. In what follows, we describe the method we use to calculate features, i.e., word-embedding. We then explain our choice of the function, i.e., neural networks.

First, we map each word into a vector of low dimension to be used in the next step. This process is called word-embedding. We have about 45,000 words in our dictionary after excluding rare words from our sample, as discussed in section 4 . One can represent each word by a vector of dimension $N$ with only one element of the vector equal to one and all other elements equal to zero. This representation has two drawbacks. First, it has a high dimension. Second, the similarity of any word to all other words is the same when measured by cosine similarity. To overcome these limitations, we employ word-embedding with a structure suggested by Mikolov

of words. Term-weighting schemes assign a weight to each word in a document to calculate a weighted sum of words.

${ }^{3}$ In a nutshell, NBC represents a document (or a sentence) by a vector that shows how often each word appears in the document. It ignores the relation between words and the sequence of words in the document. 
et al. (2013a), known as Word2Vec. Word-embedding preserves semantic and syntactic aspects of words, i.e., similar words have close vector representations (see, e.g., Mikolov et al. (2013a)). The size of these vectors can be significantly smaller than $N$ - we choose ${ }^{4} 200$ in this paper. ${ }^{5} \mathrm{We}$ implement word-embedding using more than 7 billion words and 220 million sentences from the full text of all 10-K filings by U.S. public companies made during 1994-2017.

In the next step, we train a model based on recurrent neural networks (RNN) that takes the vector representation of words in a sentence and classifies the sentiment expressed in the sentence into one of three categories: negative, positive, and neutral. Using RNN allows us to capture complex non-linear dependencies while taking into account the sequential nature of the data, i.e., a sentence. Specifically, we use a variant of RNN, called long short-term memory (LSTM). LSTM is a solution to mitigate the issue of remembering elements that are far from the end of a sequence and the problem of vanishing and exploding gradients when training the model. We train the model using 8,000 manually labeled sentences that are randomly selected from 10-K filings. The trained model achieves an in-sample accuracy of $91 \%{ }^{6}$

We then use the trained model to assign sentiment to all the sentences in each $10-\mathrm{K}$ filing. We focus on the entire 10-K filing instead of certain sections such as Management Discussion \& Analysis (MD\&A) or Risk Factors because (1) prior evidence on the information content of the sentiment in MD\&A is mixed, and (2) the Risk Factors section mainly contains negative information which is likely captured by existing methods, which do a reasonably good

${ }^{4}$ As discussed in section 3, the recommended range of vector size is between 20 and 500. A vector of size 200 results in high accuracy of the classifier in the next step. It is one of the chosen hyper-parameters of the model when training the classifier, as discussed in Appendix A.

${ }^{5}$ The idea behind the method is to maximize the probability of choosing the current word, given a set of words surrounding it in a sentence. The algorithm finds close vector representation for words that surround the current word in different sentences. The parameters associated with each word in this set up construct the vector representation.

${ }^{6} \mathrm{We}$ use a regularization method to mitigate overfitting when training the model. As a result, the out-of-sample accuracy is very close to the in-sample accuracy. 
job of identifying negative sentiment. Our measure of negative (positive) sentiment is the number of negative (positive) sentences divided by the total number of sentences in each 10-K filing.

We compare our measures of sentiment with word-based measures using Loughran and McDonald's (2011; henceforth, LM) word lists and sentence-based measures using the NBC approach. The correlation between our negative (positive) sentiment measure and word-based negative (positive) sentiment measure is $0.56(0.51)$. The corresponding correlations of our measures with NBC measures are higher at 0.93 (0.79). The average positive sentiment using deep learning and NBC methods are 5\% and 8\%, respectively, in Table 2, Panel B. Thus, the NBC approach results in a positive sentiment measure which is, on average, $60 \%$ higher than our deep learning method. Table 1 shows that $4.6 \%$ of the neutral sentences in our training set are classified as positive by the NBC method while this proportion is $1.2 \%$ using deep learning. These differences and the large difference between the accuracy of our deep learning classifier and the NBC classifier ( $90 \%$ vs. $78 \%$ ) suggest that the two can have different information content, as we find in Tables 3, 4, 9, 10, and 11. We then examine the information content of our sentiment measures for stock prices, trading volume, firm fundamentals and firm policies. ${ }^{7}$ Throughout, we repeat our analysis using the LM and NBC measures instead of our sentiment measures and compare the results. ${ }^{8}$ Note that we are not interested in comparing the predictive power of different sentiment measures. Instead, we ask the following question: Given an accurate measure of sentiment, does it have information content? Given our finding that the deep learning measure more accurately classifies the sentiment in $10 \mathrm{~K}$ filings, we examine whether

${ }^{7}$ Any test of the information content of sentiment is necessarily a joint test of the validity of the sentiment measure and its information content. NLP methods enable us to classify sentences in a way that is closest to the way a human being would and provide us with a more reliable approach for measuring sentiment than existing methods.

${ }^{8}$ For brevity, we do not tabulate results where both word-based sentiment measures and our sentiment measures appear as independent variables in the same regression. These results are similar to those shown in the tables. 
this sentiment has information content. We also compare our results with other sentiment measures to examine where the results diverge.

We start by examining the relation between our sentiment measures and the reaction of stock prices and trading volumes to the $10-\mathrm{K}$ filing. Our results show that positive (negative) sentiment predicts higher (lower) abnormal return over days $(0,+3)$ around the 10 -K filing date, i.e., the filing period. After controlling for quantitative information in the filing and other relevant variables, a one standard deviation increase in negative (positive) sentiment predicts a change in cumulative abnormal return of $-0.13 \%(0.07 \%)$. Even though the correlation between our sentiment measures and NBC measures are high, NBC sentiment measures are not significantly related to the abnormal return at $10-\mathrm{K}$ filing. Moreover, positive sentiment using LM words is not related to the filing abnormal return either.

We also find that both positive and negative sentiment are related to higher abnormal return over event windows of up to one month after the filing period. This finding suggests that the market underreacts to positive sentiment and overreacts to negative sentiment in the $10-\mathrm{K}$ filing during the filing period. LM sentiment measures fail to capture this dynamic. NBC positive sentiment exhibits weaker relations and only for longer periods after the filing date. In addition, both positive and negative sentiment measures are significantly related to abnormal trading volume around the filing date. Negative sentiment reflects more concerns and uncertainty about the future, which results in greater divergence of opinions among investors and therefore leads to higher trading volume. On the other hand, positive sentiment reflects less uncertainty about the future, which results in less divergence of opinions and lower trading volume. In multivariate analysis, a one standard deviation increase in negative (positive) sentiment predicts a 0.13 (0.04) standard deviation increase (decrease) in abnormal trading volume. This asymmetric result suggests that investors are more responsive to negative sentiment than to positive sentiment.

We next examine the relation between sentiment and future firm fundamentals. Li (2010) finds that the tone in the forward-looking statements in the MD\&A section of $10-\mathrm{K}$ is related to firm fundamentals. However, Li uses a net measure of tone by aggregating positive and negative tone. We focus on the entire $10-\mathrm{K}$ and use positive and negative sentiment measures separately. We find that positive sentiment predicts higher return on assets and higher operating cash flow over the next year, while negative sentiment predicts lower values of these performance 
measures. Positive LM sentiment predicts lower future profitability, which is counterintuitive, but consistent with the measure being inaccurate. The NBC sentiment measures have the same signs as our deep learning method, but the former have up to $60 \%$ less economic significance, particularly for positive sentiment. The economic significance of negative and positive sentiment under the deep learning method are comparable to each other, suggesting that positive sentiment is nearly as informative regarding future profitability as negative sentiment. This result holds throughout the majority of the analyses in the paper.

We next evaluate the informativeness of the sentiment in the $10-\mathrm{K}$ filing regarding future firm policies. An unfavorable business environment or greater uncertainty about a firm's future prospects should be reflected in higher negative sentiment in the filing. Managers of such firms might increase cash holding in the future to be prepared for potential losses and unexpected costs. Consistent with this argument, our results show that negative sentiment predicts higher future cash holding. Positive sentiment can reflect a strong operational and financial situation and less need to hold onto cash. It can also reflect higher growth opportunities, followed by greater spending on new projects and expansion. In any case, the result would be lower future cash holding when positive sentiment is higher. Consistent with this argument, we find that positive sentiment predicts lower future cash holding. Interestingly, the estimated coefficient of negative sentiment is approximately three times larger than that of positive sentiment in absolute value, a result that suggests that managers are more responsive when performance and outlook are weak than when they are strong.

Our finding that positive sentiment is related to higher cash flow from operations triggers a natural question: what is the extra cash flow used for? To investigate this issue, we examine the relationship between sentiment and future use of leverage. We find that a one standard deviation increase in positive sentiment predicts a 0.13 standard deviation decrease in leverage in the next period, suggesting that the extra cash generated in the future is used to reduce leverage. On the other hand, negative sentiment predicts higher leverage, but the magnitude of this relation is much smaller than that of positive sentiment. This asymmetric relation suggests that poorly performing firms have a harder time raising additional debt.

Finally, motivated by Cohen, Malloy, and Nguyen (2018), we examine whether changes in sentiment are informative. We repeat our analyses using changes, instead of levels, of 
sentiment as independent variables. We find that an increase in positive sentiment predicts higher abnormal return at the $10 \mathrm{~K}$ filing date. While the coefficient of change in negative sentiment is negative, it is statistically insignificant. Moreover, changes in sentiment predict future profitability, cash holdings, and leverage. The results for changes in positive sentiment are much stronger than for changes in negative sentiment, both statistically and economically. In contrast, changes in LM and NBC sentiment measures largely fail to predict filing abnormal returns, future profitability and leverage.

Overall, we find persuasive evidence that, in contrast to most prior studies, positive sentiment in 10-K filings is informative and that the market reacts to it. The effects of positive sentiment and negative sentiment in corporate filings are often asymmetric, which implies that using a net sentiment measure would result in loss of information. More importantly, our findings suggest that employing this state-of-the-art technique for textual analysis can provide more reliable measures of sentiment. The word-embedding matrix and the NN classifier can be shared and used easily, and researchers can improve the accuracy of the classifier by using their own labelled sentences, which would substantially reduce the cost of using this approach. Finally, in addition to measuring general sentiment in other sources of textual data in finance, this method can be used for tasks such as topic-specific content analysis, e.g., classifying text into topics such as competition, innovation or financial constraints, and to measure the tone within each topic.

The paper contributes to the literature on textual content analysis (see, e.g., Huang et al. (2017), and Li, Lundholm and Minnis (2013)) and sentiment analysis (see, e.g., Henry (2008), and Tetlock, Saar-Tsechansky and Macskassy (2008)) by introducing a novel approach. Our approach is sentence-based, rather than word-based, and hence circumvents the need to develop word lists or to choose a term-weighting scheme. This approach also makes use of the relationship between words in context and considers a sentence as a sequence of words rather than a bag-of-words in which order does not matter. These two properties are the main advantages of this approach compared to the NBC approach (see, e.g., Li (2010), and Huang, Zang and Zheng (2014)), resulting in higher accuracy of sentiment classification. More specifically, the paper contributes to the literature on sentiment analysis of 10-Ks (see, e.g., Loughran and McDonald (2011), Jegadeesh and Wu (2013)) and finds new evidence on its 
information content. More broadly, the paper contributes to the literature on qualitative information in accounting and finance (see, e.g., Mayew and Venkatachalam (2012), and Coval and Shumway (2001)). Finally, the paper contributes to the literature on corporate disclosures (see, e.g., Dyer, Lang and Stice-Lawrence (2017), and Li (2010)) by providing evidence on the information content of $10-\mathrm{K}$ filings.

\section{Related Literature}

Textual content analysis is a growing literature in finance. In this section, we briefly discuss the literature on content analysis based on the most popular methods, followed by the papers on sentiment analysis relevant to this study. Kearney and Liu (2014) and Loughran and McDonald (2016) provide detailed reviews of the finance literature on textual sentiment and textual analysis, respectively. Gentzkow, Kelly and Taddy (2019) survey statistical methods for analyzing textual data and its applications in economics and related social sciences.

One strand of this literature relies on word-based sentiment measures and field-specific dictionaries. Earlier sentiment studies use DICTION, Harvard General Inquirer, and Henry (2008) word lists to measure the tone or sentiment of a financial document. Most recent studies use Loughran and McDonald's (2011) word lists, especially their lists of negative and uncertain words, because they have been found to be more relevant to financial documents. Most prior studies find that positive words lack information content. The accuracy of the sentiment in sentences using negative word lists is in the range of $45 \%$ to $65 \%$ in different studies 9 .

Other studies develop and use topic-related word lists. Hoberg and Maksimovic (2015) use a specific word list to identify financially-constrained firms. Li, Lundholm and Minnis (2013) measure competition by counting the number of occurrences of the word compete and its variants in 10-K filings. Qiu and Wang (2017) use a word list to measure skilled labor risk that firms face. Loughran, McDonald and Yun (2009) find a relationship between ethics-related word count in 10-K filings and the probability of being a 'sin' stock.

9 The studies compute the accuracy of word-based methods by using word lists to classify sentences, instead of entire documents. As the studies point out, this is a noisy measure of accuracy because word lists are typically used in these studies to measure the sentiment of an entire document, rather than a single sentence. 
Several studies consider term-weighting schemes that place different weight on words in a document. Loughran and McDonald (2011) show that this approach can result in a better fit. Jegadeesh and $\mathrm{Wu}$ (2013) use the market reaction to annual filings to find a term-weighting scheme. They show that this approach is not sensitive to the choice of word lists because they find similar results when omitting one-half of the words in word lists or when using more general word lists.

Another strand of the content analysis literature applies techniques from NLP and machine learning. Several studies employ NBC for sentiment analysis. This approach represents a sentence or a document by a vector, each element of which equals the number of appearances of a corresponding word in the sentence. This method requires manual classification of a sample of sentences from the corpus under study to train the classifier ${ }^{10}$. Huang, Zang and Zheng (2014) and Li (2010) use this method to measure the sentiment in analyst reports and forward-looking statements in 10-K filings, respectively. Ji, Talavera and Yin (2018), Antweiler and Frank (2004), Ryans (2018), and Buehlmaier and Whited (2017) have also applied NBC in different settings. The main difference between the NBC approach and the approach we use here is that NBC considers a document as a collection of words ${ }^{11}$ and does not take into account the relationship between words and the sequential nature of text. While achieving higher accuracy than word-based sentiment measures, the NBC approach typically results in a lower level of accuracy than the approach used here. Huang, Zang and Zheng (2014) achieve 77\% accuracy in out-of-sample sentiment classification, while Li (2010) reports 67\% accuracy in 3-way

${ }^{10}$ Alternatively, a relevant observable variable can be used to determine the tone or importance of a document. Instead of using manual classification, Ryans (2018) uses abnormal return to identify SEC comment letters that are important.

${ }^{11} \mathrm{NBC}$ can add sequences of two or more words as standalone features of the document (Bigrams and $\mathrm{N}$-grams). However, the number of the parameters explodes as the sequence gets larger. Additionally, this approach is expected to work well in cases where negation is explicit and happens in a very close proximity of a positive word, e.g., "The movie was not good", which is not common in financial texts. 
classification $^{12}$. In our sample, the out-of-sample accuracy of the NBC method is $78 \%$. However, our labelled sentences contain only 10,600 unique words which is substantially less than the 45,191 total words in our dictionary. Thus, the NBC method misses the information in the majority of the words in the dictionary and the $78 \%$ number likely overestimates the real accuracy of the method. ${ }^{13}$

Finally, several studies use a topic modeling approach called Latent Dirichlet Allocation (LDA) that is most suitable for assigning interpretable topics to a document. Huang et al. (2017) use LDA to show that analysts discuss topics beyond what firms disclose. Dyer, Lang and SticeLawrence (2017) employ LDA to explore changes in 10-K disclosures over time. Bellstam, Bhagat and Cookson (2017) apply LDA, together with LM word lists, to analyst reports to construct a measure of innovation. Hanley and Hoberg (2018) use LDA, together with wordembedding that we employ in this paper, to identify interpretable emerging risks in the financial sector. While LDA has not been used for sentiment analysis in finance, it can be. Similar to word-embedding techniques, LDA outputs a vector representation of words, which can be fed to a NN to build a classifier.

Sentiment analysis in finance has established that sentiment is informative for stock prices, firm fundamentals, and the overall stock market performance. This literature uses several sources of textual data such as corporate disclosures, analyst reports, news articles, earnings conference calls, and social media. Most of the literature has focused on negative and uncertain words to measure sentiment. Tetlock, Saar-Tsechansky and Macskassy (2008) show that negative words in news stories predict earnings and that the market reacts to that information. Huang, Zang and Zheng (2014) find that negative and positive sentiment in analyst reports are related to abnormal return and future earnings growth. Feldman et al. (2010) find that changes in the tone of the management discussion and analysis (MD\&A) sections of 10-K filings are related to the filing period excess return. Li (2010), using NBC to construct a single tone measure, finds

12 The accuracy of sentiment classification is not directly comparable across different studies because they use different datasets.

13 This issue is likely to be significantly mitigated in our approach. With word-embedding, the classifier learns about 'unseen' words since words similar to them exist in the training set. 
that the tone of forward-looking statements in MD\&A predicts future profitability and liquidity. Cohen, Malloy, and Nguyen (2018) find that at the time of a 10-K or 10-Q filing, investors don't react to changes in the language used from the previous filing. But these changes, identified using document similarity measures, predict future stock returns and profitability.

Loughran and McDonald (2011) find that negative, but not positive, words in 10-K filings are related to abnormal returns around the filings. Jegadeesh and $\mathrm{Wu}$ (2013) find that both negative and positive sentiment in 10-K filings based on word lists and a term-weighting scheme are related to abnormal returns. Our study comes closest to these two papers in that they both examine the information content of the sentiment in 10-K filings. LM establish new word lists and show that negative and uncertain words are related to variables such as abnormal return, trading volume, and fraud. Loughran and McDonald (2016) caution that researchers need to deal with the negation of positive words to examine positive sentiment. Jegadeesh and $\mathrm{Wu}$ (2013)

propose a novel approach to calculate a term-weighting scheme and apply that scheme to previously developed word lists. Loughran and McDonald (2016, p. 1223) point out that while term-weighting schemes have the potential to increase the power of textual methods, researchers face too many schemes to choose from due to lack of theoretical guidelines or independent verification. In addition, this approach ignores the context in which words are used. Jegadeesh and $\mathrm{Wu}(2013)$ also make a rather strong assumption that the frequency of words used in 10-Ks is related to abnormal returns at the filing and use these returns to come up with a termweighting scheme. Our paper uses deep learning to measure sentiment more accurately and intuitively, re-examines several previously established results and finds new evidence on the information content of sentiment.

\section{Sentiment Classification}

In this section we briefly discuss the method we use for sentiment classification. A more detailed discussion is in Appendix A. Our approach is sentence-based, i.e. it assigns sentiment to each sentence. This approach classifies the sentiment in sentences similar to the way a human being (i.e., an intelligent agent) would do it. Since we use a large textual dataset, manually performing sentiment classification is nearly impossible. We borrow from the artificial intelligence literature to perform this task. 
Our approach to sentiment classification is a two-step process. First, we use a dimensionality reduction technique, i.e. word-embedding, and find vector representation of words, in which each word is represented by a vector of low dimension. The results of wordembedding depend on, among other factors, the textual data that is used. Generally, it is desirable to use as much relevant textual data as possible. To perform word-embedding, we use the full text of all 10-K filings by U.S. public companies over 1994-2017. The choice of vector size, i.e., the word-embedding dimension, is somewhat arbitrary, but is usually within the range of 20 to 500. We choose 200 as the dimension of word-embedding. Word-embedding is known to preserve semantic and syntactic features of words. Similar words have a similar representation measured by cosine similarity. In a recent study, Li, et al. (2018) use word-embedding to find words that are relevant to corporate culture. We then represent each sentence as a sequence of vectors corresponding to the words in each sentence, thus constructing a time-series for each sentence.

In the second step, we train a neural network (NN) to classify a sentence into three categories: negative, positive and neutral. The NN we use is a variant of recurrent NN (RNN) with a Softmax classifier as the output layer. RNN captures the dynamics of sequential data, which in our study is a sentence. More specifically, we employ LSTM network that enables the network to retain information from observations that are far from the end of the sequence. ${ }^{14}$ To train our NN, we manually classify 8,000 randomly selected sentences (train-set) into the three categories. The in-sample accuracy of the trained $\mathrm{NN}$ is $91 \%$. We then examine the out-ofsample performance of the classifier. We use an additional 1,500 manually labelled sentences (test-set) and find an out-of-sample accuracy of $90 \%$.

Panels A and B of Table 1 show the distribution of categories for the train-set and the test-set, respectively. Note that negative sentences that are classified as positive and vice versa are rare. Panel $\mathrm{C}$ shows the accuracy if we use LM word lists to classify sentences. This part is

${ }^{14}$ Our choice of the structure of the sentiment classifier, i.e. word-embedding followed by LSTM network, is a natural choice in NLP. Wang et al. (2015) employ the same structure to perform sentiment classification on Twitter posts. They achieve comparable accuracy to the best available data-driven approaches at the time, and higher accuracy than several feature-engineering approaches. We use the same structure but perform word-embedding independently of the RNN. 
for comparison with other studies (e.g. Huang et. al. (2014)) as the method to calculate the sentiment in a $10-\mathrm{K}$ is based on the number of words not the number of sentences. However, it illustrates that LM positive and negative words often appear in neutral contexts. Panel D presents the same analysis using NBC. The average out-of-sample accuracy of NBC with our sample of sentences is $78 \%$, which likely overestimates the method's true accuracy, as discussed in the introduction.

We use the trained NN to label all the sentences in a $10-\mathrm{K}$ filing to calculate the overall sentiment of the filing. Table A2 provides some examples of sentences we classify as negative, positive and neutral to train the NN. We also report negative (positive) words based on LM word lists in sentences in which the sentiment is not negative (positive) to illustrate that the meaning of words depends on the context in which they are used.

Our approach to sentiment classification uses the relation between words and considers a sentence as a sequence of words. The former is achieved by using word-embedding and the latter is achieved by using RNN for sentiment classification. Word-embedding enables the classifier to accurately classify sentences in out-of-sample data even if some words do not exist in the trainset. The classifier can relate the 'unseen' words to similar 'have seen' words in the train-set. This is one of the main advantages of this method compared to NBC. Overall, our approach is sentence-based, which is by its nature more accurate and intuitive than word-based measures. It also achieves high accuracy compared to the extant sentence-based methods used in finance and accounting.

\section{Data}

We obtain data on firm fundamentals from Compustat, and stock prices and trading volumes from CRSP. We compute cumulative abnormal returns using Eventus. We use the GVKEY-CIK Link table from the SEC Analytics Suites to link each 10-K filing with a Compustat firm. We obtain all $10-\mathrm{K}$ and $10-\mathrm{K} 405^{15}$ filings by U.S. public companies during

${ }^{15}$ Form $10-\mathrm{K} 405$ is a Form $10-\mathrm{K}$ that indicates that an officer or director of the company failed to file their insider trading disclosures (Forms 3, 4 and 5) on time. Form 10-K405 was discontinued after 2002. We follow Loughran and McDonald (2011) and do not include 10-KSB and 10-KSB405 filings, mostly by penny stock firms, that existed until 2009. 
1994 to 2017 from the Software Repository for Accounting and Finance (SRAF) website, maintained by Professor Bill McDonald. ${ }^{16}$ SRAF has parsed EDGAR filings to remove encodings unrelated to the textual content of the filings. We start our matching process by downloading 193,692 10-K filings, excluding duplicates and firms that file multiple filings on the same date. We then find a matching GVKEY, using the GVKEY-CIK Link table which results in 156,288 filings. Next, we find Permno match and only include share codes equal to 10 and 11 (i.e., equity securities issued by companies incorporated in the U.S.), resulting in 98,602 filings. We then exclude utility and financial firms and all filings with less than 200 sentences. For each firm, we only include the first filing for each reporting period in case of multiple reports. The final sample consists of $62,726^{17}$ firm-year observations with non-missing cumulative abnormal returns to estimate equation (1).

To perform word-embedding, 10-K filings need to be preprocessed. Inputs to the algorithm are sentences, therefore we tokenize each $10-\mathrm{K}$ filing into sentences. Next, each sentence needs to be tokenized into words. We convert all words into lowercase, exclude words that appear in less than 100 filings, and exclude words that appear less than 500 times in all of the filings combined. That procedure results in a dictionary of 45,191 words. While the choices of 100 and 500 are arbitrary, the idea is to produce a dictionary that is not too large, so as to save computational cost when performing word-embedding. The pre-processing results in 220 million sentences and 7.5 billion words in more than 190,000 10-K filings ${ }^{18}$.

After pre-processing, all the sentences are fed to an algorithm to compute the wordembedding matrix. One popular, efficient, and scalable choice for implementing word-

${ }^{16}$ Available at: http://sraf.nd.edu/

${ }^{17}$ For comparison, Jegadeesh and Wu (2013) report 45,860 filings during 1995-2010, without excluding utility firms.

${ }^{18}$ For word-embedding, it is desirable to use as much relevant text as available. So we use all filings, instead of trying to find a GVKEY or Permno match. 
embedding is the Gensim software. Specifically, we use the Word $2 \mathrm{vec}^{19}$ module that implements Mikolov's (2013a and 2013b) proposed structure. This module takes as hyper-parameters the number of surrounding words, the dimension of the word vectors, and several other parameters that determine the sampling frequency, hardware configuration, training algorithms, etc. We set the dimension of word-embedding to 200 for this study. ${ }^{20}$

To construct measures of positive and negative sentiment, we use the trained NN to classify all the sentences in each 10-K filing into positive, negative and neutral. The total number of negative (positive) sentences divided by the total number of sentences in each filing is our measure of negative (positive) sentiment. We also calculate the sentiment based on LM word lists for each filing, as defined in Appendix B. Panel A of Table 2 shows Pearson correlations between our sentiment measures and those of LM. It is interesting to note that the correlation between our and LM's negative (positive) sentiment measures is 0.56 (0.51), i.e., roughly midway between 0 and 1 . Panel B of Table 2 shows summary statistics of our sentiment measures and firm-level variables.

\section{Empirical Results}

In the previous section, we describe the process of calculating the sentiment in $10-\mathrm{K}$ filings based on the sentiment of all the sentences in each filing. We choose to analyze the full text of 10-Ks, instead of its sections such as Risk Factors or MD\&A, for two reasons. First, prior studies (e.g., Loughran and McDonald (2011)) find that the MD\&A section is not informative. Second, the Risk Factors section generally has negative sentiment which can be measured relatively accurately using negative words. The full text of $10-\mathrm{K}$ is more suitable for investigation since there are comparable studies (e.g. Loughran and McDonald (2011) and Jegadeesh and $\mathrm{Wu}(2013))$ on it, and both negative and positive sentiment is prevalent in it.

Sentiment is a general concept that is quantified. Sentences can have positive or negative sentiment, but they can be about different topics. Managers express facts and opinions on a

${ }^{19}$ Available at: https://radimrehurek.com/gensim/models/word2vec.html

${ }^{20}$ Again, while the choice of 200 is arbitrary, the idea is to get a high accuracy rate in sentiment classification, which uses the output of word-embedding, while keeping the computational cost reasonable. We get an accuracy rate of $91 \%$ in-sample and $90 \%$ out-of-sample. 
variety of topics in 10-K filings. A negative sentence can be about competition a firm faces, regulations that affect its operations and profitability, lawsuits against the firm, its inability to raise fund, the loss of key personnel, and many other issues. Each of these cases can affect firm fundamentals to different extents, but they are all expected to affect profitability negatively. In sentiment analysis, we aggregate all these topics and provide a unified measure of negative and positive sentiments.

The sentiment in a 10-K filing reflects managers' opinions of the firm's operating results over the past year and their view of what the future holds for the firm. To the extent that these opinions and views are informative beyond the quantitative information in $10-\mathrm{K}$ filings, the market should respond to them and they should be reflected in future fundamentals of the firm, on average. To test the former prediction, we examine the response of stock prices and trading volumes to the sentiment in $10-\mathrm{K}$ filings. To test the latter, we examine whether the sentiment in 10-K filings predicts future firm fundamentals.

\subsection{Does sentiment predict abnormal returns?}

The first question we address after computing an intuitive and accurate measure of sentiment is: Is the sentiment in $10-\mathrm{K}$ filings associated with abnormal stock returns around the 10-K filing date? Previous studies find that negative sentiment predicts negative abnormal return. Jegadeesh and $\mathrm{Wu}$ (2013) find that both negative and positive sentiments are associated with abnormal returns. We start by re-examining these central results and estimate the following equation:

$$
\mathrm{CAR}=\alpha+\beta_{1} . \text { Negative }+\beta_{2} \text {. Positive }+\gamma . \text { Controls }
$$

where $C A R$ is the cumulative abnormal return (based on Fama-French three factor model plus momentum) over days 0 to +3 around the filing date ${ }^{21}$, Negative and Positive are our measures of negative and positive sentiment respectively, and Controls is a set of control variables that captures quantitative information included in the 10-K filing, namely Total Assets, Tobin's Q, Market Cap., Cash, Leverage and ROA. All the variables are defined in Appendix B. Following Jegadeesh and $\mathrm{Wu}$ (2013), we also include the abnormal return over days $[-1,+1]$ around the

${ }^{21}$ Our choice of this time window to measure the abnormal return to $10-\mathrm{K}$ filings follows prior studies (see, e.g., Loughran and McDonald (2011), and Jegadeesh and Wu (2013)). 
earnings announcement (EARet) in our set of control variables in equation (1). We also estimate the same set of regressions using sentiment measures computed using word lists similar to Loughran and McDonald (2011) and NBC. For comparison, all sentiment measures are normalized to have a mean of zero and a standard deviation of one.

The results are shown in Table 3. Column 1 shows a regression that includes just our negative and positive sentiment measures and control variables. Columns 2 and 3 replace our sentiment measures with LM and NBC sentiment measures. Columns 4 to 6 add year-quarter fixed effects and industry fixed effects. In columns 7 to 9 we exclude observations for which there is an earnings announcement within 2 days prior to the $10-\mathrm{K}$ filing date. In all the specifications, higher negative sentiment predicts lower cumulative abnormal return around the filing date, which is consistent with previous studies. The coefficient of $L M N e g$, the negative sentiment calculated using LM negative word list, is also negative and statistically significant, consistent with the results of Loughran and McDonald (2011).

Notably, our positive sentiment measure predicts higher cumulative abnormal return. In line with most previous findings, the positive sentiment measured by positive words, LM Pos, is unrelated to the abnormal return in any specification. NBC sentiment measures are not related to abnormal return in any of the specifications. As shown in column 1, after including control variables, a one standard deviation increase in negative (positive) sentiment predicts a change in cumulative abnormal return of $-0.13 \%(0.07 \%)$. Not only is positive sentiment related to abnormal return, its estimated coefficient is non-trivial. In sum, both negative and positive sentiments are significantly related to abnormal return in opposite directions. Our finding that positive sentiment in a $10-\mathrm{K}$ filing predicts the abnormal return to the filing is new compared to most of the prior literature, except for Jegadeesh and Wu (2013).

We next examine whether these relationships in a short time-window after the $10-\mathrm{K}$ filing date continue or reverse over longer windows after the filing period. Consistent with Jegadeesh and $\mathrm{Wu}$ (2013), we re-estimate equation (1) after replacing the dependent variable with the cumulative abnormal return calculated over three different windows after the first trading week following the $10-\mathrm{K}$ filing. The lengths of these windows are one week ( 5 trading days), two weeks (10 trading days), and one month (22 trading days). Table 4 shows the results. Negative sentiment, which predicts lower abnormal return during the filing period, predicts higher 
abnormal return after the filing period, which suggests that the market overreacts to negative sentiment during the filing period. But positive sentiment predicts higher abnormal return both during and after the filing period, suggesting that the market underreacts to positive sentiment during the filing period ${ }^{22}$. Table 4 also shows the corresponding analysis using LM word lists and NBC. Word-based sentiment measures are unrelated to abnormal returns after the filing period. Both positive and negative NBC sentiment measures, which are unrelated to filing abnormal returns, predict higher abnormal returns after the filing period, although positive sentiment becomes significant only over longer time windows.

We also examine the performance of a trading strategy based on the sentiment measures. We rank firms with December fiscal year end at the end of March of each year based on their negative and positive sentiment. We then construct a portfolio that longs stocks in the highest (lowest) quintile of positive (negative) sentiment and short sells stocks in the lowest (highest) quintile of positive (negative) sentiment. The portfolio is rebalanced once a year at the end of March. ${ }^{23}$ We regress the return of the portfolio on Fama-French three factors and calculate alpha. In untabulated results, we find that the alpha is statistically insignificant using either our positive or negative sentiment measures. This result is consistent with Loughran and McDonald (2011).

In addition, we test whether the information environment of firms affects the market reaction at the time of $10-\mathrm{K}$ filings. One would expect that firms with low analyst coverage will have greater information asymmetry between managers and investors. Therefore, the market response to the information in 10-K filings should be stronger for such firms. On the other hand, these firms are usually smaller with less diversified operations, making them less complex with lower information asymmetry. These two effects are in an opposite direction and we cannot predict ex ante whether the market reacts more strongly to the sentiment in 10-K filings for firms with low analyst coverage or for firms with high analyst coverage. To examine this issue, we partition firms at the median based on analyst coverage into high and low coverage groups and estimate equation (1) separately for each group. We then compare the estimated coefficients. In

22 Jegadeesh and $\mathrm{Wu}$ (2013) find that the market underreacts to both sentiment measures during the filing period.

${ }^{23}$ The results are similar if we hold the portfolio for three months, instead of one year. 
untabulated results, the estimated coefficients of our sentiment measures are not statistically different between the two groups. We also partition firms based on the dispersion of analyst forecasts as an alternate measure of information asymmetry, and repeat the previous analysis. Again, we find no statistically significant difference between the estimated coefficients of the sentiment measure between the two groups.

Overall, we find that our sentiment measures predict abnormal return during and after the $10-\mathrm{K}$ filing period up to one month. LM positive sentiment is unrelated to abnormal return and LM negative sentiment only predicts abnormal return during the filing period but not after that. NBC sentiment does not predict abnormal return during the filing period and predicts return after the filing period in some specifications.

\subsection{Does sentiment predict abnormal volume?}

We next examine the relation between the sentiment measures and abnormal trading volume over days 0 to +3 around the $10-\mathrm{K}$ filing date. We estimate the same equation as in equation (1), with abnormal trading volume as the dependent variable. We calculate abnormal trading volume following Loughran and McDonald (2011) using the mean (M) and standard deviation $(\mathrm{S})$ of trading volume during the 60-day period that ends 5 days prior to the filing date. Thus, abnormal volume for a firm over day $t$ is computed as $A V_{t}=\left(V_{t}-M\right) / S$, where $V_{t}$ is its trading volume on day $\mathrm{t}$. The mean of $\mathrm{AV}_{\mathrm{t}}$ over days $\mathrm{t}=0$ to +3 is our measure of abnormal trading volume for a firm. The results are shown in Table 5.

In all specifications, higher negative sentiment predicts higher abnormal trading volume, and higher positive sentiment predicts lower abnormal trading volume. Higher negative sentiment potentially reflects more uncertainty, raises investor concerns about the firm's future and increases asymmetric information among investors, resulting in higher divergence of investors' opinion and higher abnormal trading volume. On the other hand, higher positive sentiment signals that managers expect less uncertainty about the future and reflects more resolved concerns that firms might have faced, resulting in lower abnormal trading volume. The results are similar when using NBC, but LM word lists provide mixed results. In column (1), a one standard deviation increase in negative (positive) sentiment predicts $0.65 / 4.94=0.13$ $(0.18 / 4.94=0.04)$ standard deviation increase (decrease) in abnormal trading volume. The absolute values of the estimated coefficients of negative and positive sentiment are statistically 
different at the $1 \%$ level of significance. This asymmetric result suggests that investors are more responsive to negative sentiment than to positive sentiment.

Overall, we find in section 5 so far that positive sentiment, as well as negative sentiment, predicts filing period abnormal return and abnormal trading volume. In addition, the results on abnormal return after the filing period and the asymmetric results on trading volume suggest that positive sentiment is by nature different from negative sentiment. When manually labeling 9,500 sentences, we observe that positive and negative sentences tend to discuss different topics. Aggregating these two measures to construct a net sentiment measure would likely result in loss of information embedded in them. Our results in the next sub-section further support this idea.

\subsection{Does sentiment predict future firm fundamentals?}

In their annual reports, firms usually discuss their outlook on the economy, industry, and firm, disclose risk factors, explain the firm's future directions, and report key factors affecting revenues and expenses. Whether this textual information, and the sentiment expressed in it, contains information regarding future firm fundamentals that is not captured by the quantitative information in the report is an empirical question. Most prior studies find that only negative sentiment has information content about firm fundamentals. In this section, we re-examine these findings and also investigate whether positive sentiment is informative.

We start by estimating the following regression:

$$
\operatorname{ROA}_{(t+1)}=\alpha+\beta_{1} . \text { Negative }_{(t)}+\beta_{2} . \text { Positive }_{(t)}+\gamma . \text { Controls }_{(t)}
$$

where $R O A$ is the return on assets, Negative and Positive are normalized measures of negative and positive sentiment, and Controls is a set of control variables found by the prior literature to affect profitability. The coefficients of interest are $\beta_{1}$ and $\beta_{2}$. In a series of specifications, we successively add year-quarter and industry fixed effects. The results in panel A of Table 6 support the idea that the sentiment conveyed by managers in the $10-\mathrm{K}$ filing is informative about future firm profitability. Positive sentiment predicts higher future $R O A$ and negative sentiment predicts lower future ROA. In column (1), a one standard deviation increase in positive (negative) sentiment predicts 1.7 (2.8) percentage point increase (decrease) in ROA the next year. When we repeat this analysis using sentiment measures based on word lists, while the results are similar for negative sentiment, positive sentiment predicts lower future profitability. These 
results suggest that our deep learning approach adds considerable value, especially for measuring positive sentiment. The NBC sentiment measures predict future ROA similar to our measures, but its positive sentiment is economically less significant than the deep learning approach in all three specifications. In untabulated results, we find qualitatively similar results when using net income as the left-hand side variable.

Next, we estimate the regression in equation 2 using Op. CFlow $(t+1)$ as the dependent variable. Op. CFlow is net operating cash flow divided by total assets. The results in panel B of Table 6 show that positive (negative) 10-K sentiment predicts higher (lower) cash flow the next year. In column (1), a one standard deviation increase in positive (negative) sentiment predicts a $+1.4(-1.9)$ percentage point change in future operating cash flow. Here too, positive sentiment is informative and its effect is roughly of the same order of magnitude as the negative sentiment. When we repeat this analysis with sentiment measures using word lists, negative sentiment significantly predicts lower future Op. CFlow. But the coefficient of positive sentiment is also negative, consistent with the conclusion of previous studies that find that positive sentiment based on positive word lists provides an inaccurate measure of sentiment (see, e.g., the review by Loughran and McDonald (2016)). Using NBC sentiment measures provides qualitatively similar results to our deep learning approach. In sum, the results in Table 6 suggest that both measures of sentiment using the deep learning method are informative with respect to future profitability in an intuitive manner, and their relationship with future profitability is not symmetric.

\subsection{Does sentiment predict future firm policies?}

As numerous prior studies (see, e.g., Bates, Kahle, and Stulz (2009), and Acharya, Davydenko, and Strebulaev (2012)) find, managers use cash holding as a precautionary measure against risk, which should be reflected in the sentiment in annual reports. Negative sentiment generally reflects poor past performance or increased uncertainty and concern about the future, which implies higher future cash holding. Positive sentiment, on the other hand, generally reflects past performance that exceeds expectations, a favorable business environment or higher growth opportunities, which suggest lower future cash holding because managers are less concerned about risks or they increase investment spending. To investigate this issue, we estimate equation (2) after replacing the dependent variable with Cash $_{t+1}$, defined as cash plus cash equivalents divided by total assets. The results in Table 7 show that the estimated 
coefficients of our sentiment measures are consistently significant across all specifications and have opposite signs. Negative sentiment predicts higher future cash holding, while positive sentiment predicts lower future cash holding. The absolute value of the estimated coefficient of negative sentiment is about three times that of positive sentiment and they are statistically different from each other at the $1 \%$ level. This asymmetric result suggests that managers respond in the face of uncertainty and negative outlook by raising cash holdings more than they reduce them when the outlook is favorable. When measured using word lists, both negative and positive sentiments predict higher future cash holdings, which is counterintuitive. This result supports previous studies about the unreliability of positive sentiment measure using word lists and is in line with the results in Tables 3, 4 and 6. The results using NBC sentiment measures are qualitatively similar to our deep learning measures, though the economic significance of NBC positive sentiment is somewhat weaker.

Our results so far show that positive sentiment predicts higher future operating cash flow, higher profitability, but lower cash holding. What is the extra cash generated from operations used for? One possibility is that it is used to pay off debt. To find out if this is the case, we examine the relation between sentiment and future leverage. We estimate the regression in equation (2) with Leverage $_{t+1}$ as the dependent variable. Table 8 shows that positive sentiment predicts lower future leverage ratio, suggesting that the extra cash generated from operations is used to reduce leverage. On the other hand, negative sentiment is marginally associated with higher future leverage. The magnitude of the estimated coefficient of the positive sentiment is about 4 to 9 times larger than that of the negative sentiment and they are statistically different at the $1 \%$ level. This asymmetric result is consistent with the hypothesis that firms that express high negative sentiment have less flexibility to change their leverage ratio than firms with high positive sentiment. The results using LM sentiment and NBC positive measures are consistent with our deep learning measures, but NBC negative sentiment has no predictive power.

In untabulated results, positive (negative) sentiment predicts higher (lower) valuation, measured by Tobin's Q the next year. We measure $\mathrm{Q}$ as (the market value of common stock + book values of preferred stock, long-term debt and debt in current liabilities) divided by the book value of total assets. We also examine whether our sentiment measures predict investment activities in the future. We find that neither negative nor positive sentiment predicts investments 
(measured by capital expenditures, R\&D expenses, or changes in net or gross property, plant and equipment (PP\&E), each scaled by total assets at the beginning of the fiscal year) during the next year. There are two potential explanations of this result. First, investment activities are determined by long-term considerations and are not affected by temporary business environments, which are reflected in the sentiment in annual reports. Second, the overall sentiment in annual reports is a noisy measure of investment plans and outlook discussed in 10Ks. We leave a fuller investigation of this issue to future research.

\subsection{Information content of changes in sentiment}

Our final set of analyses examines whether the change in sentiment in 10-Ks relative to last year is informative. Cohen, Malloy, and Nguyen (2018) find that firms that change the language in their $10 \mathrm{~K}$ filings experience negative future stock returns that reflect changes in firm fundamentals, but investors are inattentive to these changes. Motivated by their findings, we next examine whether changes in the level of sentiment predict abnormal stock returns at the $10 \mathrm{~K}$ filing, and future fundamentals and firm policies. Accordingly, we repeat our analyses in prior sections after replacing sentiment levels by their first differences as our main explanatory variables $^{24}$. We start by examining the stock price reaction around the $10 \mathrm{~K}$ filing. In different specifications, we exclude observations with an earnings announcement close to the filing date, as in section 5.1, and include year-quarter and industry fixed effects. Table 9 presents the results. Change in positive sentiment predicts positive filing abnormal returns, but change is negative sentiment does not. Changes in LM and NBC sentiment measures do not predict filing abnormal returns.

Table 10 examines the predictive power of sentiment changes on future profitability and cash flow. In Panel A, higher positive (negative) sentiment predicts higher (lower) future profitability. For changes in LM and NBC measures, negative sentiment does not matter, while higher positive sentiment predicts higher future profitability in most specifications. In Panel B,

24 The correlation between changes in positive sentiment and changes in negative sentiment is 0.51. To explore whether the lower power of our results in this section is due to multicollinearity, we include only the change in one sentiment measure. The results are qualitatively very similar, suggesting that multicollinearity is not a big concern here. 
only the change in our positive sentiment matters for cash flow. Higher positive sentiment predicts higher future operating cash flow. LM and NBC sentiment measures are insignificant.

Finally, Table 11 shows this analysis on future cash holdings and leverage. In Panel A, changes in both our sentiment measures significantly predict future cash holdings. Higher negative (positive) sentiment predicts higher (lower) cash holdings. Changes in NBC sentiment measures yield similar results. For LM measures, only positive sentiment changes significantly predict (higher) cash holdings. In Panel B, only our positive sentiment measure significantly predicts (lower) future leverage. Coefficients of changes in LM and NBC sentiment measures are insignificant.

In sum, we find that changes in sentiment measures, especially positive sentiment, contain information about future firm fundamentals and that the market reacts to that information. This information also leads to changes in future firm policies.

\section{Conclusion}

This paper brings state-of-the-art techniques from natural language processing and deep learning to finance for content analysis and sentiment classification. We apply word-embedding to find vector representation of words that preserves semantic and syntactic features of words, and apply deep learning to train a sentiment-classifier. The trained sentiment-classifier achieves an out-of-sample accuracy of $90 \%$. We then examine the information content of positive and negative sentiment measures based on our NN classifier. Unlike prior studies based on wordbased classifiers, we find that both negative and positive sentiments are informative. Positive (negative) sentiment predicts higher (lower) abnormal return and lower (higher) abnormal trading volume around the $10-\mathrm{K}$ filing date. The market overreacts to negative sentiment and underreacts to positive sentiment during the filing period. All of these effects are larger for negative sentiment than for positive sentiment. Positive sentiment also predicts higher future profitability, higher operating cash flow, lower cash holding, and lower financial leverage. Negative sentiment predicts these variables in the opposite direction. Except for cash holding, the magnitudes of these effects are greater for positive sentiment than for negative sentiment. We

find generally similar results when we examine the change in sentiment instead of its level. We conclude that (1) the text of corporate annual reports has richer information content than 
previously found, (2) positive sentiment is also informative besides negative sentiment, and (3) calculating a net sentiment measure would likely result in loss of information.

The deep learning method used in this paper provides an intuitive, interpretable, and verifiable sentiment measure, and circumvents the need to develop word lists and term-weighting schemes. Moreover, researchers using textual data in non-English languages with no established finance word lists can also use this method. In addition to general sentiment analysis, this method can be applied to content analysis in specific areas. Examples of topics that firms discuss in annual reports are innovation, competition, access to external financing and the risk posed by large customers and suppliers. Researchers can extract information on such topics in a way similar to a classification task. Exploring the economic mechanisms that explain the predictive power of sentiment and investigating managers' strategic disclosure behavior are other promising pathways for future research. Considering the vast amount of textual data (e.g., various corporate disclosures, analyst reports, conference calls, news articles, and social media) and new textual analysis techniques such as the deep learning technique introduced in this paper, this is an exciting research area that holds much promise. 


\section{References}

Acharya, Viral, Sergei A. Davydenko, and Ilya A. Strebulaev. Cash holdings and credit risk. Review of Financial Studies 25, no. 12 (2012): 3572-3609.

Antweiler, Werner, and Murray Z. Frank. Is all that talk just noise? The information content of internet stock message boards. Journal of Finance 59, no. 3 (2004): 1259-1294.

Bates, Thomas W., Kathleen M. Kahle, and René M. Stulz. Why do US firms hold so much more cash than they used to? Journal of Finance 64, no. 5 (2009): 1985-2021.

Bellstam, Gustaf, Sanjai Bhagat, and J. Anthony Cookson. Innovation in Mature Firms: A TextBased Analysis. (2017). Working paper, SSRN.

Buehlmaier, Matthias MM, and Toni M. Whited. Are financial constraints priced? Evidence from textual analysis. Review of Financial Studies 31, no. 7 (2018): 2693-2728.

Chollet, Franois. Keras: The Python Deep Learning Library (2015). https://keras.io

Cohen, Lauren, Christopher Malloy, and Quoc Nguyen. Lazy prices. Working paper no. w25084. National Bureau of Economic Research, 2018.

Coval, Joshua D., and Tyler Shumway. Is sound just noise? Journal of Finance 56, no. 5 (2001): 1887-1910.

Dyer, Travis, Mark Lang, and Lorien Stice-Lawrence. The evolution of 10-K textual disclosure: Evidence from Latent Dirichlet Allocation. Journal of Accounting and Economics 64, no. 2-3 (2017): 221-245.

Fama, Eugene F., and Kenneth R. French. Common risk factors in the returns on stocks and bonds. Journal of Financial Economics 33, no. 1 (1993): 3-56.

Feldman, Ronen, Suresh Govindaraj, Joshua Livnat, and Benjamin Segal. Management's tone change, post earnings announcement drift and accruals. Review of Accounting Studies 15, no. 4 (2010): 915-953.

Gentzkow, Matthew, Bryan T. Kelly, and Matt Taddy. Text as data. Journal of Economic Literature, forthcoming (2019). 
Hanley, Kathleen Weiss, and Gerard Hoberg. Dynamic interpretation of emerging risks in the financial sector. (2018). Working paper, SSRN.

Henry, Elaine. Are investors influenced by how earnings press releases are written? Journal of Business Communication (1973) 45, no. 4 (2008): 363-407.

Hoberg, Gerard, and Vojislav Maksimovic. Redefining financial constraints: A text-based analysis. Review of Financial Studies 28, no. 5 (2014): 1312-1352.

Hochreiter, Sepp, and Jürgen Schmidhuber. Long short-term memory. Neural Computation 9, no. 8 (1997): 1735-1780.

Huang, Allen H., Reuven Lehavy, Amy Y. Zang, and Rong Zheng. Analyst information discovery and interpretation roles: A topic modeling approach. Management Science 64, no. 6 (2017): 2833-2855.

Huang, Allen H., Amy Y. Zang, and Rong Zheng. Evidence on the information content of text in analyst reports. Accounting Review 89, no. 6 (2014): 2151-2180.

Jegadeesh, Narasimhan, and Di Wu. Word power: A new approach for content analysis. Journal of Financial Economics 110, no. 3 (2013): 712-729.

Ji, Jiao, Oleksandr Talavera, and Shuxing Yin. The Hidden Information Content: Evidence from the Tone of Independent Director Reports. (2018). Working paper, SSRN.

Kearney, Colm, and Sha Liu. Textual sentiment in finance: A survey of methods and models. International Review of Financial Analysis 33 (2014): 171-185.

Li, Feng. The information content of forward-looking statements in corporate filings-A naïve Bayesian machine learning approach. Journal of Accounting Research 48, no. 5 (2010): 10491102.

Li, Feng, Russell Lundholm, and Michael Minnis. A measure of competition based on 10-K filings. Journal of Accounting Research 51, no. 2 (2013): 399-436.

Li, Kai, Feng Mai, Rui Shen, and Xinyan Yan. Corporate Culture and Merger Success: Evidence from Machine Learning. (2018) Working paper. 
Loughran, Tim, Bill McDonald, and Hayong Yun. A wolf in sheep's clothing: The use of ethicsrelated terms in 10-K reports. Journal of Business Ethics 89, no. 1 (2009): 39-49.

Loughran, Tim, and Bill McDonald. When is a liability not a liability? Textual analysis, dictionaries, and 10-Ks. Journal of Finance 66, no. 1 (2011): 35-65.

Loughran, Tim, and Bill McDonald. Textual analysis in accounting and finance: A survey. Journal of Accounting Research 54, no. 4 (2016): 1187-1230.

Mayew, William J., and Mohan Venkatachalam. The power of voice: Managerial affective states and future firm performance. Journal of Finance 67, no. 1 (2012): 1-43.

Mikolov, Tomas, Kai Chen, Greg Corrado, and Jeffrey Dean. Efficient estimation of word representations in vector space. arXiv preprint arXiv:1301.3781 (2013a).

Mikolov, Tomas, Ilya Sutskever, Kai Chen, Greg S. Corrado, and Jeff Dean. Distributed representations of words and phrases and their compositionality. In Advances in Neural Information Processing Systems, (2013b): 3111-3119.

Qiu, Yue, and Tracy Yue Wang. Skilled Labor Risk and Compensation Policies. (2017). Working paper, SSRN.

Rehurek, Radim, and Petr Sojka. Software framework for topic modelling with large corpora. In Proceedings of the LREC 2010 Workshop on New Challenges for NLP Frameworks.

Ryans, James. Textual classification of SEC comment letters. (2018). Working paper, SSRN.

Tetlock, Paul C., Maytal Saar-Tsechansky, and Sofus Macskassy. More than words: Quantifying language to measure firms' fundamentals. Journal of Finance 63, no. 3 (2008): 1437-1467.

Wang, Xin, Yuanchao Liu, S. U. N. Chengjie, Baoxun Wang, and Xiaolong Wang. Predicting polarities of tweets by composing word-embeddings with long short-term memory. In Proceedings of the 53rd Annual Meeting of the Association for Computational Linguistics and the 7th International Joint Conference on Natural Language Processing (Volume 1: Long Papers, 2015): 1343-1353. 


\section{Table 1: Accuracy of alternative classification methods}

This table reports the distribution of sentences into three sentiment categories: negative, positive, and neutral. Panel A (B) shows the train-set (test-set), which consists of 8,000 $(1,500)$ sentences. The sum of the percentages on the main diagonal in each panel measures the accuracy of the NN classification. We use stratified random sampling to select 9,500 sentences to assure that the data is balanced, i.e. the neutral category does not dominate the sample. Stratifies are based on Loughran and McDonald's (2011) word lists. 2,000 sentences are completely random; 5,000 sentences include at least one word from LM's negative or positive word lists; 2,000 sentences include at least one word from their list of uncertain words, and 500 sentences include at least on word from their list of constraint words. Panel $\mathrm{C}$ shows the classification based on LM word lists. A sentence is positive (negative, neutral) if the number of positive words minus the number of negative words in the sentence is positive (negative, zero). Panel D shows the classification based on NBC classifier. Numbers are the average of 10-fold out-of-sample accuracy. Sentences are randomly partitioned into 10 groups. 10 NBC classifiers are trained each time on $90 \%$ of the data. The accuracy is calculated on the $10 \%$ out-of-sample data each time.

\section{Panel A: Train-Set (8,000 Sentences)}

\begin{tabular}{cllcl} 
& & \multicolumn{3}{c}{ Manually Labeled } \\
Neural Network & Negative & $20.3 \%$ & $2.2 \%$ & $0.4 \%$ \\
Classification & Neutral & $3.5 \%$ & $64.8 \%$ & $2.0 \%$ \\
& Positive & $0.2 \%$ & $1.2 \%$ & $5.4 \%$
\end{tabular}

\section{Panel B: Test-Set (1,500 Sentences)}

$\begin{array}{cllll} & & \text { Negative } & \text { Neutral } & \text { Positive } \\ \text { Neural Network } & \text { Negative } & 20.2 \% & 2.3 \% & 0.3 \% \\ \text { Classification } & \text { Neutral } & 4.0 \% & 63.5 \% & 2.2 \% \\ & \text { Positive } & 0.1 \% & 1.5 \% & 5.9 \%\end{array}$

Panel C: Classification Using LM word list (9,500 Sentences)

\begin{tabular}{cllcl} 
& & \multicolumn{3}{c}{ Manually Labeled } \\
Classification & Negative & $17.1 \%$ & Neutral & Positive \\
Based on LM & Neutral & $4.2 \%$ & $28.0 \%$ & $0.9 \%$ \\
words & Positive & $2.6 \%$ & $26.6 \%$ & $1.6 \%$ \\
& & $13.6 \%$ & $5.4 \%$
\end{tabular}

Panel D: NBC Classification (Average 10-fold out-of-sample)

Manually Labeled

$\begin{array}{cllll} & & \text { Negative } & \text { Neutral } & \text { Positive } \\ \text { Naïve Bayes } & \text { Negative } & 19.1 \% & 8.8 \% & 2.0 \% \\ \text { Classification } & \text { Neutral } & 4.3 \% & 54.9 \% & 2.1 \% \\ & \text { Positive } & 0.4 \% & 4.6 \% & 3.7 \%\end{array}$




\section{Table 2: Correlations and summary statistics}

Panel A shows Pearson correlations among the sentiment measures. Panel B shows summary statistics of sentiment measures, firm fundamentals, cumulative abnormal returns, and abnormal trading volume. Variables are defined in Appendix B.

Panel A

$\begin{array}{lcccccc} & \text { Negative } & \text { Positive } & \text { LM Neg } & \text { LM Pos } & \text { NBC Neg } & \text { NBC Pos } \\ \text { Negative } & 1 & & & & & \\ \text { Positive } & 0.23 & 1 & & & & \\ \text { LM Neg } & 0.56 & -0.15 & 1 & & & \\ \text { LM Pos } & 0.27 & 0.51 & 0.06 & 1 & & \\ \text { NBC Neg } & 0.93 & 0.33 & 0.42 & 0.31 & 1 & \\ \text { NBC Pos } & 0.15 & 0.79 & -0.25 & 0.43 & 0.26 & 1\end{array}$

Panel B

$\begin{array}{llll} & \text { Count } & \text { Mean } & \text { Sd } \\ \text { Negative } & 62726 & 0.12 & 0.06 \\ \text { Positive } & 62726 & 0.05 & 0.03 \\ \text { LM Neg } & 62726 & 0.016 & 0.004 \\ \text { LM Pos } & 62726 & 0.006 & 0.002 \\ \text { NBC Neg } & 62726 & 0.18 & 0.08 \\ \text { NBC Pos } & 62726 & 0.08 & 0.04 \\ \text { Assets (\$million) } & 62726 & 2983 & 18206 \\ \text { Market Cap. (\$million) } & 62683 & 3304 & 17407 \\ \text { Leverage } & 62456 & 0.22 & 0.22 \\ \text { Cash } & 62711 & 0.23 & 0.25 \\ \text { ROA } & 62453 & 0.03 & 0.36 \\ \text { R\&D } & 62726 & 0.08 & 0.17 \\ \text { Tobin's Q } & 62382 & 1.93 & 2.00 \\ \text { Op. CFlow } & 62539 & 0.01 & 0.30 \\ \text { Tangibility } & 62650 & 0.24 & 0.22 \\ \text { B/M } & 62643 & 0.57 & 0.62 \\ \text { EARet } & 61134 & 0.05 \% & 9.5 \% \\ \text { Abn. Trading volume } & 62726 & 1.42 & 4.94 \\ \text { CAR(0, +3) } & 62726 & -0.35 \% & 8.3 \%\end{array}$




\section{Table 3: Filing abnormal return and sentiment}

The table presents estimates of the OLS regressions of $\operatorname{CAR}(0,+3)$, the cumulative abnormal return in percentages over days 0 to +3 around the $10-\mathrm{K}$ filing date. Abnormal return is computed using the three Fama and French factors and momentum. The main explanatory variables of interest are Negative and Positive, LM Neg and LM Pos, and NBC Neg and NBC Pos. Negative (Positive) is the ratio of the number of negative (positive) sentences based on our deep learning approach to the total number of sentences in a 10-K filing. LM Neg (LM Pos) is the ratio of the number of negative (positive) words based on Loughran and McDonald's (2011) word lists to the total number of words in a filing. Positive words that are preceded within the last three words by $\{$ no, not, none, neither, never, nobody $\}$ are considered negative. NBC Neg (NBC Pos) is the ratio of the number of negative (positive) sentences based on Naïve Bayes classifier to the total number of sentences in a 10-K filing. Columns 7, 8, and 9 exclude filings for which there is an earnings announcement within 2 days before the $10 \mathrm{~K}$ filing date. All sentiment measures are normalized to have a mean of 0 and a standard deviation of 1 . Control variables are Total Assets, Tobin's Q, Market Cap., Cash, Leverage, ROA, and EARet, as defined in Appendix B. Year_Quarter fixed effect is based on the year and quarter of the filing date. Industry fixed effect is based on Fama and French (1993) 48-industry classification. The coefficients of the constant, control variables, and fixed effects are omitted for brevity. Standard errors are in parentheses and are clustered by firm. ***, **, and * indicate statistical significance at $1 \%, 5 \%$, and $10 \%$ levels, respectively.

Dependent variable: $\operatorname{CAR}(0,+3)$

\begin{tabular}{|c|c|c|c|c|c|c|c|c|c|}
\hline $\begin{array}{l}\text { Independent } \\
\text { variables }\end{array}$ & (1) & $(2)$ & (3) & (4) & $(5)$ & $(6)$ & $(7)$ & $(8)$ & (9) \\
\hline Negative & $\begin{array}{c}-0.13 * * * \\
(0.038)\end{array}$ & & & $\begin{array}{c}-0.14 * * * \\
(0.051)\end{array}$ & & & $\begin{array}{c}-0.19 * * * \\
(0.056)\end{array}$ & & \\
\hline Positive & $\begin{array}{l}0.07 * * \\
(0.034)\end{array}$ & & & $\begin{array}{l}0.09 * * \\
(0.036)\end{array}$ & & & $\begin{array}{l}0.09 * * \\
(0.037)\end{array}$ & & \\
\hline LM Neg & & $\begin{array}{c}-0.09 * * \\
(0.035)\end{array}$ & & & $\begin{array}{l}-0.08^{*} \\
(0.041)\end{array}$ & & & $\begin{array}{r}-0.15^{* * *} \\
(0.042)\end{array}$ & \\
\hline LM Pos & & $\begin{array}{c}0.01 \\
(0.034)\end{array}$ & & & $\begin{array}{c}0.01 \\
(0.036)\end{array}$ & & & $\begin{array}{c}-0.01 \\
(0.034)\end{array}$ & \\
\hline NBC Neg & & & $\begin{array}{l}-0.06 \\
(0.037)\end{array}$ & & & $\begin{array}{c}-0.06 \\
(0.051)\end{array}$ & & & $\begin{array}{c}-0.08 \\
(0.056)\end{array}$ \\
\hline NBC Pos & & & $\begin{array}{c}0.01 \\
(0.035)\end{array}$ & & & $\begin{array}{c}0.04 \\
(0.039)\end{array}$ & & & $\begin{array}{c}0.03 \\
(0.039)\end{array}$ \\
\hline Obs. & 60,536 & 60,536 & 60,536 & 60,103 & 60,103 & 60,103 & 44,514 & 44,514 & 44,514 \\
\hline Adj. R-sq. & 0.062 & 0.062 & 0.062 & 0.063 & 0.063 & 0.062 & 0.005 & 0.005 & 0.005 \\
\hline Controls & Yes & Yes & Yes & Yes & Yes & Yes & Yes & Yes & Yes \\
\hline YQ FE & & & & Yes & Yes & Yes & Yes & Yes & Yes \\
\hline Ind. FE & & & & Yes & Yes & Yes & Yes & Yes & Yes \\
\hline
\end{tabular}




\section{Table 4: Post-filing abnormal return and sentiment}

The table presents estimates of OLS regressions of CAR $(+5+T)$, the cumulative abnormal return, in percentages over days +5 to $+\mathrm{T}$ following the $10-\mathrm{K}$ filing date. Abnormal return is computed using the three Fama and French factors and momentum. The main explanatory variables of interest are Negative and Positive, LM Neg and LM Pos, and NBC Neg and NBC Pos. Negative (Positive) is the ratio of the number of negative (positive) sentences based on our deep learning approach to the total number of sentences for each filing. LM Neg (LM Pos) is the ratio of the number of negative (positive) words based on Loughran and McDonald's (2011) word lists to the total number of words. Positive words that are preceded within the last three words by \{no, not, none, neither, never, nobody\} are considered negative. NBC Neg (NBC Pos) is the ratio of the number of negative (positive) sentences based on Naïve Bayes classifier to the total number of sentences in a 10-K filing. All sentiment measures are normalized to have a mean of 0 and a standard deviation of 1. All the columns include control variables and Year_Quarter and Industry fixed effects. Control variables are Total Assets, Tobin's Q, Market Cap., Cash, Leverage, $R O A$, and EARet, as defined in Appendix B. Year_Quarter fixed effect is based on the year and quarter of filing date. Industry fixed effect is based on Fama and French (1993) 48-industry classification. The coefficients of the constant, control variables, and fixed effects are omitted for brevity. Standard errors are in parentheses and are clustered by firm. ${ }^{* *}, * *$, and * indicate statistical significance at $1 \%, 5 \%$, and $10 \%$ levels, respectively.

Dependent variable

\begin{tabular}{|c|c|c|c|c|c|c|c|c|c|}
\hline \multirow[b]{2}{*}{ Ind. Variables } & \multicolumn{3}{|c|}{$\operatorname{CAR}(+5,+9)$} & \multicolumn{3}{|c|}{$\operatorname{CAR}(+5,+14)$} & \multicolumn{3}{|c|}{ CAR $(+5,+26)$} \\
\hline & (1) & (2) & (3) & (4) & $(5)$ & (6) & $(7)$ & $(8)$ & (9) \\
\hline Negative & $\begin{array}{l}0.11^{* *} \\
(0.051)\end{array}$ & & & $\begin{array}{c}0.25 * * * \\
(0.073)\end{array}$ & & & $\begin{array}{c}0.32 * * * \\
(0.107)\end{array}$ & & \\
\hline Positive & $\begin{array}{l}0.08^{* *} \\
(0.037)\end{array}$ & & & $\begin{array}{c}0.18 * * * \\
(0.052)\end{array}$ & & & $\begin{array}{c}0.36^{* * *} \\
(0.077)\end{array}$ & & \\
\hline LM Neg & & $\begin{array}{c}0.01 \\
(0.040)\end{array}$ & & & $\begin{array}{c}0.07 \\
(0.059)\end{array}$ & & & $\begin{array}{c}0.08 \\
(0.085)\end{array}$ & \\
\hline LM Pos & & $\begin{array}{c}0.01 \\
(0.035)\end{array}$ & & & $\begin{array}{c}0.06 \\
(0.050)\end{array}$ & & & $\begin{array}{c}0.10 \\
(0.077)\end{array}$ & \\
\hline NBC Neg & & & $\begin{array}{c}0.14 * * * \\
(0.052)\end{array}$ & & & $\begin{array}{c}0.29 * * * \\
(0.074)\end{array}$ & & & $\begin{array}{c}0.31 \text { *** } \\
(0.108)\end{array}$ \\
\hline NBC Pos & & & $\begin{array}{c}0.05 \\
(0.040)\end{array}$ & & & $\begin{array}{c}0.09^{*} \\
(0.056)\end{array}$ & & & $\begin{array}{c}0.25^{* * *} \\
(0.082)\end{array}$ \\
\hline Obs. & 60,031 & 60,031 & 60,031 & 60,031 & 60,031 & 60,031 & 60,033 & 60,033 & 60,033 \\
\hline Adj. R-sq. & 0.009 & 0.008 & 0.009 & 0.016 & 0.015 & 0.016 & 0.036 & 0.036 & 0.036 \\
\hline
\end{tabular}




\section{Table 5: Abnormal trading volume and sentiment}

The table presents estimates of OLS regressions of the average abnormal trading volume, Abnormal Volume $(A V)$, in a stock over days $\mathrm{t}=0$ to +3 around the $10-\mathrm{K}$ filing date. $\mathrm{AV}$ equals the mean of $\mathrm{AV}_{\mathrm{t}}$ over days $\mathrm{t}=0$ to $+3 . \mathrm{AV}_{\mathrm{t}}=\left(\mathrm{V}_{\mathrm{t}}-\mathrm{M}\right) / \mathrm{S}$, where $\mathrm{V}_{\mathrm{t}}$ is the trading volume in a stock on day $\mathrm{t}$. $\mathrm{M}$ is the mean, and $\mathrm{S}$ is the standard deviation of its trading volume during the 60-day period that ends five days prior to the filing date. Negative (Positive) is the ratio of the number of negative (positive) sentences based on our deep learning approach to the total number of sentences in a 10-K filing. LM Neg (LM Pos) is the ratio of the number of negative (positive) words based on Loughran and McDonald's (2011) word lists to the total number of words. Positive words that are preceded within the last three words, by no, not, none, neither, never, nobody $\}$ are considered negative. NBC Neg (NBC Pos) is the ratio of the number of negative (positive) sentences based on Naïve Bayes classifier to the total number of sentences in a 10-K filing. Columns 7,8, and 9 exclude filings for which there is an earnings announcement within 2 days prior to the $10 \mathrm{~K}$ filing date. All sentiment measures are normalized to have a mean of 0 and a standard deviation of 1 . The standard deviation of the dependent variable is 4.94. Control variables are Total Assets, Tobin's Q, Market Cap., Cash, Leverage, and ROA, as defined in Appendix B. Year_Quarter fixed effect is based on the year and quarter of the filing date. Industry fixed effect is based on Fama and French (1993) 48-industry classification. The coefficients of the constant, control variables, and fixed effects are omitted for brevity. Standard errors are in parentheses and are clustered by firm. ***, $* *$, and $*$ indicate statistical significance at $1 \%, 5 \%$, and $10 \%$ levels, respectively.

Dependent variable: Abnormal Volume

\begin{tabular}{|c|c|c|c|c|c|c|c|c|c|}
\hline Ind. variables & $(1)$ & $(2)$ & (3) & (4) & (5) & (6) & $(7)$ & $(8)$ & (9) \\
\hline Negative & $\begin{array}{c}0.65^{* * *} \\
(0.03)\end{array}$ & & & $\begin{array}{c}0.16^{* * *} \\
(0.04)\end{array}$ & & & $\begin{array}{l}0.06^{* *} \\
(0.03)\end{array}$ & & \\
\hline Positive & $\begin{array}{c}-0.18 * * * \\
(0.03)\end{array}$ & & & $\begin{array}{c}-0.14 * * * \\
(0.03)\end{array}$ & & & $\begin{array}{c}-0.06^{* * * *} \\
(0.02)\end{array}$ & & \\
\hline LM Neg & & $\begin{array}{c}0.39 * * * \\
(0.03)\end{array}$ & & & $\begin{array}{c}0.09 * * * \\
(0.03)\end{array}$ & & & $\begin{array}{c}0.02 \\
(0.02)\end{array}$ & \\
\hline LM Pos & & $\begin{array}{l}-0.02 \\
(0.03)\end{array}$ & & & $\begin{array}{c}-0.08 * * * \\
(0.03)\end{array}$ & & & $\begin{array}{l}-0.02 \\
(0.02)\end{array}$ & \\
\hline NBC Neg & & & $\begin{array}{c}0.67 * * * \\
(0.03)\end{array}$ & & & $\begin{array}{c}0.18^{* * *} \\
(0.04)\end{array}$ & & & $\begin{array}{l}0.07 * * \\
(0.03)\end{array}$ \\
\hline NBC Pos & & & $\begin{array}{c}-0.33 * * * \\
(0.02)\end{array}$ & & & $\begin{array}{c}-0.15^{* * *} \\
(0.03)\end{array}$ & & & $\begin{array}{c}-0.05^{* *} \\
(0.02)\end{array}$ \\
\hline Obs. & 62,107 & 62,107 & 62,107 & 61,660 & 61,660 & 61,660 & 44,507 & 44,507 & 44,507 \\
\hline Adj. R-sq. & 0.015 & 0.007 & 0.017 & 0.043 & 0.042 & 0.043 & 0.010 & 0.010 & 0.010 \\
\hline Controls & Yes & Yes & Yes & Yes & Yes & Yes & Yes & Yes & Yes \\
\hline YQ FE & & & & Yes & Yes & Yes & Yes & Yes & Yes \\
\hline Ind. FE & & & & Yes & Yes & Yes & Yes & Yes & Yes \\
\hline
\end{tabular}




\section{Table 6: Future profitability and sentiment}

The table presents estimates of OLS regressions of a profitability measure. In panel A, the dependent variable is $R O A_{(t+1)}$, with a standard deviation of 0.36 . In panel $\mathrm{B}$, the dependent variable is $O p$. CFlow $_{(t+1)}$, the net operating cash flow from the Cash Flow Statement divided by total assets, with a standard deviation of 0.3 . All independent variables have subscript $t$, which denotes the year of the $10-\mathrm{K}$ reporting period. Negative (Positive) is the ratio of the number of negative (positive) sentences based on our deep learning approach to the total number of sentences in a filing. LM Neg (LM Pos) is the ratio of the number of negative (positive) words based on Loughran and McDonald's (2011) word lists to the total number of words in a filing. Positive words that are preceded within the last three words by no, not, none, neither, never, nobody $\}$ are considered negative. NBC Neg (NBC Pos) is the ratio of the number of negative (positive) sentences based on Naïve Bayes classifier to the total number of sentences in a $10-\mathrm{K}$ filing. All sentiment measures are normalized to have a mean of 0 and a standard deviation of 1 . Control variables are defined in Appendix B. Year_Quarter fixed effect is based on the year and quarter of the $10-\mathrm{K}$ reporting period. Industry fixed effect is based on Fama and French (1993) 48-industry classification. The coefficients of the constant and fixed effects are omitted for brevity. Standard errors are in parentheses and are clustered by firm. $* * *, * *$, and $*$ indicate statistical significance at $1 \%, 5 \%$, and $10 \%$ levels, respectively.

\begin{tabular}{|c|c|c|c|c|c|c|c|c|c|}
\hline $\begin{array}{l}\text { Panel A } \\
\text { Ind. Var. }\end{array}$ & (1) & $(2)$ & (3) & $\begin{array}{l}\text { Depenc } \\
\text { (4) }\end{array}$ & $\begin{array}{l}\text { ent variable } \\
\text { (5) }\end{array}$ & $\begin{array}{r}\mathrm{ROA}_{\mathrm{t}+1} \\
\text { (6) }\end{array}$ & (7) & (8) & (9) \\
\hline Negative & $\begin{array}{c}-0.028^{* * *} \\
(0.001)\end{array}$ & & & $\begin{array}{c}-0.021^{* * *} \\
(0.002)\end{array}$ & & & $\begin{array}{c}-0.013 * * * \\
(0.002)\end{array}$ & & \\
\hline Positive & $\begin{array}{c}0.017 * * * \\
(0.001)\end{array}$ & & & $\begin{array}{c}0.016^{* * *} \\
(0.001)\end{array}$ & & & $\begin{array}{c}0.012 * * * \\
(0.001)\end{array}$ & & \\
\hline LM Neg & & $\begin{array}{c}-0.017 * * * \\
(0.001)\end{array}$ & & & $\begin{array}{c}-0.010^{* * *} \\
(0.001)\end{array}$ & & & $\begin{array}{c}-0.007 * * * \\
(0.001)\end{array}$ & \\
\hline LM Pos & & $\begin{array}{c}-0.016^{* * *} \\
(0.001)\end{array}$ & & & $\begin{array}{c}-0.015^{* * * *} \\
(0.001)\end{array}$ & & & $\begin{array}{c}-0.007 * * * \\
(0.001)\end{array}$ & \\
\hline NBC Neg & & & $\begin{array}{c}-0.026^{* * *} \\
(0.001)\end{array}$ & & & $\begin{array}{c}-0.020^{* * *} \\
(0.002)\end{array}$ & & & $\begin{array}{c}-0.008 * * * \\
(0.002)\end{array}$ \\
\hline NBC Pos & & & $\begin{array}{c}0.012 * * * \\
(0.001)\end{array}$ & & & $\begin{array}{c}0.009 * * * \\
(0.001)\end{array}$ & & & $\begin{array}{c}0.005^{* * *} \\
(0.001)\end{array}$ \\
\hline ROA & $\begin{array}{c}0.508^{* * *} \\
(0.011)\end{array}$ & $\begin{array}{c}0.514 * * * \\
(0.011)\end{array}$ & $\begin{array}{c}0.513 * * * \\
(0.011)\end{array}$ & $\begin{array}{c}0.506^{* * *} \\
(0.011)\end{array}$ & $\begin{array}{c}0.509^{* * *} \\
(0.011)\end{array}$ & $\begin{array}{c}0.511^{* * *} \\
(0.011)\end{array}$ & $\begin{array}{c}0.480^{* * *} \\
(0.011)\end{array}$ & $\begin{array}{c}0.482 * * * \\
(0.011)\end{array}$ & $\begin{array}{c}0.484 * * * \\
(0.011)\end{array}$ \\
\hline $\mathrm{B} / \mathrm{M}$ & $\begin{array}{c}0.026 * * * \\
(0.002)\end{array}$ & $\begin{array}{c}0.022 * * * \\
(0.002)\end{array}$ & $\begin{array}{c}0.023 * * * \\
(0.002)\end{array}$ & $\begin{array}{c}0.026^{* * *} \\
(0.003)\end{array}$ & $\begin{array}{c}0.022 * * * \\
(0.002)\end{array}$ & $\begin{array}{c}0.023 * * * \\
(0.003)\end{array}$ & $\begin{array}{c}0.014 * * * \\
(0.002)\end{array}$ & $\begin{array}{c}0.012 * * * \\
(0.002)\end{array}$ & $\begin{array}{c}0.012 * * * \\
(0.002)\end{array}$ \\
\hline Market & & & & & & & & & \\
\hline Cap. & $\begin{array}{c}0.018^{* * *} \\
(0.001)\end{array}$ & $\begin{array}{c}0.018 * * * \\
(0.001)\end{array}$ & $\begin{array}{c}0.018 * * * \\
(0.001)\end{array}$ & $\begin{array}{c}0.019 * * * \\
(0.001)\end{array}$ & $\begin{array}{c}0.019 * * * \\
(0.001)\end{array}$ & $\begin{array}{c}0.018 * * * \\
(0.001)\end{array}$ & $\begin{array}{c}0.018 * * * \\
(0.001)\end{array}$ & $\begin{array}{c}0.019 * * * \\
(0.001)\end{array}$ & $\begin{array}{c}0.018 * * * \\
(0.001)\end{array}$ \\
\hline ROA Vol. & $\begin{array}{c}-0.153 * * * \\
(0.028)\end{array}$ & $\begin{array}{c}-0.168^{* * *} \\
(0.028)\end{array}$ & $\begin{array}{c}-0.156^{* * *} \\
(0.028)\end{array}$ & $\begin{array}{c}-0.150 * * * \\
(0.028)\end{array}$ & $\begin{array}{c}-0.163^{* * * *} \\
(0.028)\end{array}$ & $\begin{array}{c}-0.154 * * * \\
(0.028)\end{array}$ & $\begin{array}{c}-0.129 * * * \\
(0.027)\end{array}$ & $\begin{array}{c}-0.135^{* * *} \\
(0.027)\end{array}$ & $\begin{array}{c}-0.133 * * * \\
(0.027)\end{array}$ \\
\hline
\end{tabular}




\begin{tabular}{|c|c|c|c|c|c|c|c|c|c|}
\hline Ret. Vol. & $\begin{array}{c}-0.189 * * * \\
(0.015)\end{array}$ & $\begin{array}{c}-0.193 * * * \\
(0.015)\end{array}$ & $\begin{array}{c}-0.205^{* * *} \\
(0.015)\end{array}$ & $\begin{array}{c}-0.235^{* * *} \\
(0.017)\end{array}$ & $\begin{array}{c}-0.250 * * * \\
(0.017)\end{array}$ & $\begin{array}{c}-0.248 * * * \\
(0.017)\end{array}$ & $\begin{array}{c}-0.217 * * * \\
(0.017)\end{array}$ & $\begin{array}{c}-0.224 * * * \\
(0.017)\end{array}$ & $\begin{array}{c}-0.230 * * * \\
(0.017)\end{array}$ \\
\hline Obs. & 53,830 & 53,830 & 53,830 & 53,830 & 53,830 & 53,830 & 53,488 & 53,488 & 53,488 \\
\hline Adj. R-sq. & 0.562 & 0.559 & 0.560 & 0.565 & 0.564 & 0.563 & 0.586 & 0.585 & 0.584 \\
\hline YQ FE & & & & Yes & Yes & Yes & Yes & Yes & Yes \\
\hline Ind. FE & & & & & & & Yes & Yes & Yes \\
\hline
\end{tabular}

Panel B

Ind. Var.

\begin{tabular}{|c|c|c|c|c|c|c|c|c|c|}
\hline Negative & $\begin{array}{c}-0.019^{* * *} \\
(0.001)\end{array}$ & & & $\begin{array}{c}-0.014 * * * \\
(0.001)\end{array}$ & & & $\begin{array}{c}-0.008^{* * *} \\
(0.002)\end{array}$ & & \\
\hline Positive & $\begin{array}{c}0.014 * * * \\
(0.001)\end{array}$ & & & $\begin{array}{c}0.013 * * * \\
(0.001)\end{array}$ & & & $\begin{array}{c}0.010 * * * \\
(0.001)\end{array}$ & & \\
\hline LM Neg & & $\begin{array}{c}-0.013 * * * \\
(0.001)\end{array}$ & & & $\begin{array}{c}-0.009^{* * *} \\
(0.001)\end{array}$ & & & $\begin{array}{c}-0.007^{* * *} \\
(0.001)\end{array}$ & \\
\hline LM Pos & & $\begin{array}{c}-0.014 * * * \\
(0.001)\end{array}$ & & & $\begin{array}{c}-0.014 * * * \\
(0.001)\end{array}$ & & & $\begin{array}{c}-0.006^{* * *} \\
(0.001)\end{array}$ & \\
\hline NBC Neg & & & $\begin{array}{c}-0.018^{* * *} \\
(0.001)\end{array}$ & & & $\begin{array}{c}-0.013^{* * *} * \\
(0.002)\end{array}$ & & & $\begin{array}{c}-0.004 * * \\
(0.002)\end{array}$ \\
\hline NBC Pos & & & $\begin{array}{c}0.010^{* * *} \\
(0.001)\end{array}$ & & & $\begin{array}{c}0.008^{* * *} \\
(0.001)\end{array}$ & & & $\begin{array}{c}0.005^{* * *} \\
(0.001)\end{array}$ \\
\hline Op. CFlow & $\begin{array}{c}0.483 * * * \\
(0.010)\end{array}$ & $\begin{array}{c}0.483 * * * \\
(0.010)\end{array}$ & $\begin{array}{c}0.486^{* * *} \\
(0.010)\end{array}$ & $\begin{array}{c}0.480^{* * *} \\
(0.010)\end{array}$ & $\begin{array}{c}0.480 * * * \\
(0.010)\end{array}$ & $\begin{array}{c}0.484 * * * \\
(0.010)\end{array}$ & $\begin{array}{c}0.448 * * * \\
(0.010)\end{array}$ & $\begin{array}{c}0.450^{* * * *} \\
(0.010)\end{array}$ & $\begin{array}{c}0.451^{* * *} \\
(0.010)\end{array}$ \\
\hline $\mathrm{B} / \mathrm{M}$ & $\begin{array}{c}0.033 * * * \\
(0.002)\end{array}$ & $\begin{array}{c}0.029 * * * \\
(0.002)\end{array}$ & $\begin{array}{c}0.031 * * * \\
(0.002)\end{array}$ & $\begin{array}{c}0.031 * * * \\
(0.002)\end{array}$ & $\begin{array}{c}0.027 * * * \\
(0.002)\end{array}$ & $\begin{array}{c}0.029 * * * \\
(0.002)\end{array}$ & $\begin{array}{c}0.021 * * * \\
(0.002)\end{array}$ & $\begin{array}{c}0.020^{* * *} \\
(0.002)\end{array}$ & $\begin{array}{c}0.020^{* * * *} \\
(0.002)\end{array}$ \\
\hline Market Cap. & $\begin{array}{c}0.015^{* * *} \\
(0.001)\end{array}$ & $\begin{array}{c}0.016^{* * *} \\
(0.001)\end{array}$ & $\begin{array}{c}0.015^{* * *} \\
(0.001)\end{array}$ & $\begin{array}{c}0.016^{* * * *} \\
(0.001)\end{array}$ & $\begin{array}{c}0.017 * * * \\
(0.001)\end{array}$ & $\begin{array}{c}0.016^{* * *} \\
(0.001)\end{array}$ & $\begin{array}{c}0.015^{* * *} \\
(0.001)\end{array}$ & $\begin{array}{c}0.016^{* * *} \\
(0.001)\end{array}$ & $\begin{array}{c}0.015^{* * *} \\
(0.001)\end{array}$ \\
\hline ROA Vol. & $\begin{array}{c}-0.161^{* * *} \\
(0.024)\end{array}$ & $\begin{array}{c}-0.173 * * * \\
(0.024)\end{array}$ & $\begin{array}{c}-0.165^{* * *} \\
(0.024)\end{array}$ & $\begin{array}{c}-0.159^{* * *} \\
(0.023)\end{array}$ & $\begin{array}{c}-0.169 * * * \\
(0.023)\end{array}$ & $\begin{array}{c}-0.163 * * * \\
(0.024)\end{array}$ & $\begin{array}{c}-0.144 * * * \\
(0.022)\end{array}$ & $\begin{array}{c}-0.148 * * * \\
(0.022)\end{array}$ & $\begin{array}{c}-0.147 * * * \\
(0.022)\end{array}$ \\
\hline Ret. Vol. & $\begin{array}{c}-0.158^{* * *} \\
(0.013)\end{array}$ & $\begin{array}{c}-0.158^{* * *} \\
(0.013)\end{array}$ & $\begin{array}{c}-0.171 * * * \\
(0.013)\end{array}$ & $\begin{array}{c}-0.196^{* * *} \\
(0.014)\end{array}$ & $\begin{array}{c}-0.201 * * * \\
(0.014)\end{array}$ & $\begin{array}{c}-0.206^{* * *} \\
(0.014)\end{array}$ & $\begin{array}{c}-0.196^{* * *} \\
(0.014)\end{array}$ & $\begin{array}{c}-0.195^{* * *} \\
(0.014)\end{array}$ & $\begin{array}{c}-0.205^{* * *} \\
(0.014)\end{array}$ \\
\hline Obs. & 53,845 & 53,845 & 53,845 & 53,845 & 53,845 & 53,845 & 53,504 & 53,504 & 53,504 \\
\hline $\begin{array}{l}\text { Adj. R-sq. } \\
\text { YQ FE } \\
\text { Ind FE }\end{array}$ & 0.507 & 0.506 & 0.505 & $\begin{array}{c}0.509 \\
\text { Yes }\end{array}$ & $\begin{array}{c}0.509 \\
\text { Yes }\end{array}$ & $\begin{array}{c}0.507 \\
\text { Yes }\end{array}$ & $\begin{array}{c}0.532 \\
\text { Yes } \\
\text { Yes }\end{array}$ & $\begin{array}{c}0.532 \\
\text { Yes } \\
\text { Yes }\end{array}$ & $\begin{array}{c}0.531 \\
\text { Yes } \\
\text { Yes }\end{array}$ \\
\hline
\end{tabular}

Dependent variable: Op. CFlow ${ }_{t+1}$

(4)

(5)

$(7)$
$(7)$

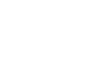




\section{Table 7: Future cash holdings and sentiment}

The table presents estimates of OLS regressions of $\mathrm{Cash}_{t+1}$, which equals (cash plus cash equivalents) divided by Total Assets. All independent variables have subscript $t$, which denotes the year of the 10-K reporting period. Negative (Positive), LM Neg (LM Pos), and NBC Neg (NBC Pos) are sentiment measures and defined in Table 6. All sentiment measures are normalized to have a mean of 0 and a standard deviation of 1 . The standard deviation of the dependent variable is 0.25 . Control variables are defined in Appendix B. Year_Quarter fixed effect and industry fixed effect are defined in Table 6. The coefficients of the constant and fixed effects are omitted for brevity. Standard errors are in parentheses and are clustered by firm. ***,**, and * indicate statistical significance at $1 \%, 5 \%$, and $10 \%$ levels, respectively.

\begin{tabular}{|c|c|c|c|c|c|c|c|c|c|}
\hline \multirow[b]{2}{*}{ Ind. Var. } & \multirow[b]{2}{*}{ (1) } & \multicolumn{8}{|c|}{ Dependent variable: Cash $_{t+1}$} \\
\hline & & $(2)$ & (3) & (4) & (5) & (6) & (7) & (8) & (9) \\
\hline Negative & $\begin{array}{c}0.010^{* * *} \\
(0.001)\end{array}$ & & & $\begin{array}{c}0.010 * * * \\
(0.001)\end{array}$ & & & $\begin{array}{c}0.009 * * * \\
(0.001)\end{array}$ & & \\
\hline Positive & $\begin{array}{c}-0.003 * * * \\
(0.000)\end{array}$ & & & $\begin{array}{c}-0.003^{* * *} \\
(0.000)\end{array}$ & & & $\begin{array}{c}-0.003 * * * \\
(0.000)\end{array}$ & & \\
\hline LM Neg & & $\begin{array}{c}0.008^{* * *} \\
(0.000)\end{array}$ & & & $\begin{array}{c}0.006^{* * *} \\
(0.001)\end{array}$ & & & $\begin{array}{c}0.005^{* * *} \\
(0.001)\end{array}$ & \\
\hline LM Pos & & $\begin{array}{c}0.006 * * * \\
(0.001)\end{array}$ & & & $\begin{array}{c}0.006 * * * \\
(0.001)\end{array}$ & & & $\begin{array}{c}0.004^{* * *} \\
(0.001)\end{array}$ & \\
\hline NBC Neg & & & $\begin{array}{c}0.009 * * * \\
(0.001)\end{array}$ & & & $\begin{array}{c}0.009 * * * \\
(0.001)\end{array}$ & & & $\begin{array}{c}0.008^{* * *} \\
(0.001)\end{array}$ \\
\hline NBC Pos & & & $\begin{array}{c}-0.002^{* * *} \\
(0.000)\end{array}$ & & & $\begin{array}{c}-0.001 * * * \\
(0.000)\end{array}$ & & & $\begin{array}{c}-0.002^{* * *} \\
(0.001)\end{array}$ \\
\hline Cash & $\begin{array}{c}0.840^{* * *} \\
(0.004)\end{array}$ & $\begin{array}{c}0.838^{* * *} \\
(0.004)\end{array}$ & $\begin{array}{c}0.842^{* * *} \\
(0.004)\end{array}$ & $\begin{array}{c}0.837^{* * *} \\
(0.004)\end{array}$ & $\begin{array}{c}0.835^{* * *} \\
(0.004)\end{array}$ & $\begin{array}{c}0.839 * * * \\
(0.004)\end{array}$ & $\begin{array}{c}0.812^{* * *} \\
(0.004)\end{array}$ & $\begin{array}{c}0.814^{* * *} \\
(0.004)\end{array}$ & $\begin{array}{c}0.814^{* * *} \\
(0.004)\end{array}$ \\
\hline $\mathrm{B} / \mathrm{M}$ & $\begin{array}{c}-0.005^{* * *} \\
(0.001)\end{array}$ & $\begin{array}{c}-0.004^{* * *} \\
(0.001)\end{array}$ & $\begin{array}{c}-0.004^{* * *} \\
(0.001)\end{array}$ & $\begin{array}{c}-0.008^{* * *} \\
(0.001)\end{array}$ & $\begin{array}{c}-0.007^{* * *} \\
(0.001)\end{array}$ & $\begin{array}{c}-0.007^{* * *} \\
(0.001)\end{array}$ & $\begin{array}{c}-0.005^{* * *} \\
(0.001)\end{array}$ & $\begin{array}{c}-0.004^{* * *} \\
(0.001)\end{array}$ & $\begin{array}{c}-0.004^{* * *} \\
(0.001)\end{array}$ \\
\hline ROA & $\begin{array}{c}-0.002 \\
(0.003)\end{array}$ & $\begin{array}{l}-0.001 \\
(0.003)\end{array}$ & $\begin{array}{c}-0.004 \\
(0.003)\end{array}$ & $\begin{array}{l}-0.002 \\
(0.003)\end{array}$ & $\begin{array}{l}-0.001 \\
(0.003)\end{array}$ & $\begin{array}{c}-0.004 \\
(0.003)\end{array}$ & $\begin{array}{c}0.001 \\
(0.003)\end{array}$ & $\begin{array}{c}0.002 \\
(0.003)\end{array}$ & $\begin{array}{c}-0.000 \\
(0.003)\end{array}$ \\
\hline Log(Sale) & $\begin{array}{c}-0.005^{* * *} \\
(0.000)\end{array}$ & $\begin{array}{c}-0.005^{* * *} \\
(0.000)\end{array}$ & $\begin{array}{c}-0.004^{* * *} \\
(0.000)\end{array}$ & $\begin{array}{c}-0.005^{* * *} \\
(0.000)\end{array}$ & $\begin{array}{c}-0.006 * * * \\
(0.000)\end{array}$ & $\begin{array}{c}-0.005^{* * *} \\
(0.000)\end{array}$ & $\begin{array}{c}-0.004^{* * *} \\
(0.000)\end{array}$ & $\begin{array}{c}-0.005^{* * *} \\
(0.000)\end{array}$ & $\begin{array}{c}-0.004^{* * *} \\
(0.000)\end{array}$ \\
\hline Sales & & & & & & & & & \\
\hline Growth & $\begin{array}{c}-0.016^{* * *} \\
(0.001)\end{array}$ & $\begin{array}{c}-0.016^{* * *} \\
(0.001)\end{array}$ & $\begin{array}{c}-0.016^{* * * *} \\
(0.001)\end{array}$ & $\begin{array}{c}-0.016^{* * *} \\
(0.001)\end{array}$ & $\begin{array}{c}-0.016 * * * \\
(0.001)\end{array}$ & $\begin{array}{c}-0.016^{* * *} \\
(0.001)\end{array}$ & $\begin{array}{c}-0.015^{* * *} \\
(0.001)\end{array}$ & $\begin{array}{c}-0.015^{* * *} \\
(0.001)\end{array}$ & $\begin{array}{c}-0.015^{* * *} \\
(0.001)\end{array}$ \\
\hline ROA. Vol. & $\begin{array}{c}0.003 \\
(0.009)\end{array}$ & $\begin{array}{c}0.006 \\
(0.009)\end{array}$ & $\begin{array}{c}0.004 \\
(0.009)\end{array}$ & $\begin{array}{c}0.004 \\
(0.009)\end{array}$ & $\begin{array}{c}0.007 \\
(0.009)\end{array}$ & $\begin{array}{c}0.005 \\
(0.009)\end{array}$ & $\begin{array}{c}0.006 \\
(0.009)\end{array}$ & $\begin{array}{c}0.008 \\
(0.009)\end{array}$ & $\begin{array}{c}0.006 \\
(0.009)\end{array}$ \\
\hline Ret. Vol. & $\begin{array}{c}0.041^{* * *} \\
(0.006)\end{array}$ & $\begin{array}{c}0.039 * * * \\
(0.006)\end{array}$ & $\begin{array}{c}0.046 * * * \\
(0.006)\end{array}$ & $\begin{array}{c}0.024 * * * \\
(0.007)\end{array}$ & $\begin{array}{c}0.029 * * * \\
(0.007)\end{array}$ & $\begin{array}{c}0.031^{* * *} \\
(0.007)\end{array}$ & $\begin{array}{c}0.024^{* * *} \\
(0.007)\end{array}$ & $\begin{array}{c}0.027^{* * *} \\
(0.007)\end{array}$ & $\begin{array}{c}0.029 * * * \\
(0.007)\end{array}$ \\
\hline Obs. & 52,948 & 52,948 & 52,948 & 52,948 & 52,948 & 52,948 & 52,662 & 52,662 & 52,662 \\
\hline Adj. R-sq. & 0.815 & 0.815 & 0.815 & 0.817 & 0.817 & 0.817 & 0.820 & 0.819 & 0.819 \\
\hline YQ FE & & & & Yes & Yes & Yes & Yes & Yes & Yes \\
\hline Ind. FE & & & & & & & Yes & Yes & Yes \\
\hline
\end{tabular}




\section{Table 8: Future leverage and sentiment}

The table presents estimates of OLS regressions of Leverage $_{t+1}$, defined as (long term debt plus debt in current liabilities) divided by Total Assets. All independent variables have subscript $t$, which denotes the year of the 10-K reporting period. Negative (Positive), LM Neg (LM Pos), and NBC Neg (NBC Pos) are sentiment measures and defined in Table 6. All sentiment measures are normalized to have a mean of 0 and a standard deviation of 1 . The standard deviation of the dependent variable is 0.22 . Control variables are defined in Appendix B. Year_Quarter fixed effect is based on year and quarter of the 10-K reporting period. Industry fixed effect is based on Fama and French (1993) 48-industry classification. The coefficients of the constant and fixed effects are omitted for brevity. Standard errors are in parentheses and are clustered by firm. ***,**, and * indicate statistical significance at $1 \%, 5 \%$, and $10 \%$ levels, respectively.

Dependent variable: Leverage $\mathrm{t}_{\mathrm{t}+1}$

\begin{tabular}{|c|c|c|c|c|c|c|c|c|c|}
\hline Ind. Var. & (1) & (2) & (3) & (4) & (5) & (6) & (7) & (8) & (9) \\
\hline Negative & $\begin{array}{c}0.003 \\
(0.002)\end{array}$ & & & $\begin{array}{l}0.004^{*} \\
(0.002)\end{array}$ & & & $\begin{array}{c}0.005^{* *} \\
(0.002)\end{array}$ & & \\
\hline Positive & $\begin{array}{c}-0.028^{* * *} \\
(0.002)\end{array}$ & & & $\begin{array}{c}-0.027^{* * *} \\
(0.002)\end{array}$ & & & $\begin{array}{c}-0.020 * * * \\
(0.002)\end{array}$ & & \\
\hline LM Neg & & $\begin{array}{c}0.007^{* * *} \\
(0.002)\end{array}$ & & & $\begin{array}{c}0.009 * * * \\
(0.002)\end{array}$ & & & $\begin{array}{c}0.010^{* * *} \\
(0.002)\end{array}$ & \\
\hline LM Pos & & $\begin{array}{c}-0.015^{* * *} \\
(0.002)\end{array}$ & & & $\begin{array}{c}-0.015^{* * *} \\
(0.002)\end{array}$ & & & $\begin{array}{c}-0.015^{* * *} \\
(0.002)\end{array}$ & \\
\hline NBC Neg & & & $\begin{array}{c}-0.003 \\
(0.002)\end{array}$ & & & $\begin{array}{c}0.000 \\
(0.002)\end{array}$ & & & $\begin{array}{c}0.000 \\
(0.002)\end{array}$ \\
\hline NBC Pos & & & $\begin{array}{c}-0.027^{* * *} \\
(0.002)\end{array}$ & & & $\begin{array}{c}-0.029 * * * \\
(0.002)\end{array}$ & & & $\begin{array}{c}-0.022^{* * *} \\
(0.002)\end{array}$ \\
\hline Tobin's Q & $\begin{array}{c}0.003^{* * *} \\
(0.001)\end{array}$ & $\begin{array}{c}0.002^{* *} \\
(0.001)\end{array}$ & $\begin{array}{c}0.002^{* * *} \\
(0.001)\end{array}$ & $\begin{array}{l}0.002^{*} \\
(0.001)\end{array}$ & $\begin{array}{c}0.001 \\
(0.001)\end{array}$ & $\begin{array}{c}0.001 \\
(0.001)\end{array}$ & $\begin{array}{c}0.001 \\
(0.001)\end{array}$ & $\begin{array}{c}0.001 \\
(0.001)\end{array}$ & $\begin{array}{c}0.001 \\
(0.001)\end{array}$ \\
\hline Cash & $\begin{array}{c}-0.279 * * * \\
(0.010)\end{array}$ & $\begin{array}{c}-0.268^{* * *} \\
(0.010)\end{array}$ & $\begin{array}{c}-0.267^{* * *} \\
(0.010)\end{array}$ & $\begin{array}{c}-0.280 * * * \\
(0.010)\end{array}$ & $\begin{array}{c}-0.266^{* * *} \\
(0.010)\end{array}$ & $\begin{array}{c}-0.267^{* * *} \\
(0.010)\end{array}$ & $\begin{array}{c}-0.288^{* * *} \\
(0.010)\end{array}$ & $\begin{array}{c}-0.280^{* * *} \\
(0.010)\end{array}$ & $\begin{array}{c}-0.277^{* * *} \\
(0.010)\end{array}$ \\
\hline ROA & $\begin{array}{c}-0.090 * * * \\
(0.005)\end{array}$ & $\begin{array}{c}-0.096^{* * *} \\
(0.005)\end{array}$ & $\begin{array}{c}-0.090^{* * *} \\
(0.005)\end{array}$ & $\begin{array}{c}-0.087^{* * *} \\
(0.005)\end{array}$ & $\begin{array}{c}-0.094^{* * *} \\
(0.005)\end{array}$ & $\begin{array}{c}-0.087^{* * *} \\
(0.005)\end{array}$ & $\begin{array}{c}-0.082^{* * *} \\
(0.005)\end{array}$ & $\begin{array}{c}-0.085^{* * *} \\
(0.005)\end{array}$ & $\begin{array}{c}-0.082^{* * *} \\
(0.005)\end{array}$ \\
\hline$R \& D$ & $\begin{array}{c}-0.029 * * * \\
(0.011)\end{array}$ & $\begin{array}{l}-0.017 \\
(0.012)\end{array}$ & $\begin{array}{l}-0.016 \\
(0.011)\end{array}$ & $\begin{array}{c}-0.036^{* * *} \\
(0.012)\end{array}$ & $\begin{array}{c}-0.025^{* *} \\
(0.012)\end{array}$ & $\begin{array}{c}-0.024^{* *} \\
(0.012)\end{array}$ & $\begin{array}{c}-0.044^{* * *} \\
(0.012)\end{array}$ & $\begin{array}{c}-0.036^{* * *} \\
(0.012)\end{array}$ & $\begin{array}{c}-0.035^{* * *} \\
(0.012)\end{array}$ \\
\hline Total & & & & & & & & & \\
\hline Assets & $\begin{array}{c}0.019 * * * \\
(0.001)\end{array}$ & $\begin{array}{c}0.019 * * * \\
(0.001)\end{array}$ & $\begin{array}{c}0.019 * * * \\
(0.001)\end{array}$ & $\begin{array}{c}0.019 * * * \\
(0.001)\end{array}$ & $\begin{array}{c}0.019 * * * \\
(0.001)\end{array}$ & $\begin{array}{c}0.019 * * * \\
(0.001)\end{array}$ & $\begin{array}{c}0.016 * * * \\
(0.001)\end{array}$ & $\begin{array}{c}0.017^{* * *} \\
(0.001)\end{array}$ & $\begin{array}{c}0.016^{* * *} \\
(0.001)\end{array}$ \\
\hline Tangibility & $\begin{array}{c}0.147^{* * *} \\
(0.011)\end{array}$ & $\begin{array}{c}0.167^{* * *} \\
(0.011)\end{array}$ & $\begin{array}{c}0.155^{* * *} \\
(0.011)\end{array}$ & $\begin{array}{c}0.140 * * * \\
(0.011)\end{array}$ & $\begin{array}{c}0.159 * * * \\
(0.011)\end{array}$ & $\begin{array}{c}0.146 * * * \\
(0.011)\end{array}$ & $\begin{array}{c}0.146 * * * \\
(0.014)\end{array}$ & $\begin{array}{c}0.150 * * * \\
(0.014)\end{array}$ & $\begin{array}{c}0.148^{* * *} \\
(0.014)\end{array}$ \\
\hline Obs. & 59,146 & 59,146 & 59,146 & 59,146 & 59,146 & 59,146 & 58,770 & 58,770 & 58,770 \\
\hline Adj. R-sq. & 0.217 & 0.208 & 0.218 & 0.229 & 0.221 & 0.231 & 0.270 & 0.269 & 0.272 \\
\hline YQ FE & & & & Yes & Yes & Yes & Yes & Yes & Yes \\
\hline Ind. FE & & & & & & & Yes & Yes & Yes \\
\hline
\end{tabular}




\section{Table 9: Change in sentiment and filing abnormal return}

The table presents estimates of the OLS regressions of $\operatorname{CAR}(0,+3)$, the cumulative abnormal return in percentages over days 0 to +3 around the $10-\mathrm{K}$ filing date. Abnormal return is computed using the three Fama and French factors and momentum. The main explanatory variables of interest are first difference $(\triangle)$ in Negative and Positive, LM Neg and LM Pos, and NBC Neg and NBC Pos. Negative (Positive) is the ratio of the number of negative (positive) sentences based on our deep learning approach to the total number of sentences in a $10-\mathrm{K}$ filing. $L M$ Neg (LM Pos) is the ratio of the number of negative (positive) words based on Loughran and McDonald's (2011) word lists to the total number of words in a filing. Positive words that are preceded within the last three words by \{no, not, none, neither, never, nobody are considered negative. NBC Neg (NBC Pos) is the ratio of the number of negative (positive) sentences based on Naïve Bayes classifier to the total number of sentences in a 10-K filing. Columns 4,5, and 6 exclude filings for which there is an earnings announcement within 2 days prior to the $10 \mathrm{~K}$ filing date. All independent variables are normalized to have a mean of 0 and a standard deviation of 1 . Control variables are Total Assets, Tobin's Q, Market Cap., Cash, Leverage, ROA, and EARet, as defined in Appendix B. Year_Quarter fixed effect is based on the year and quarter of the filing date. Industry fixed effect is based on Fama and French (1993) 48-industry classification. The coefficients of the constant, control variables, and fixed effects are omitted for brevity. Standard errors are in parentheses and are clustered by firm. $* * *$, $* *$, and * indicate statistical significance at $1 \%, 5 \%$, and $10 \%$ levels, respectively.

Dependent variable: $\operatorname{CAR}(0,+3)$

\begin{tabular}{|c|c|c|c|c|c|c|c|c|c|}
\hline Ind. Var. & (1) & (2) & (3) & (4) & (5) & (6) & (7) & $(8)$ & (9) \\
\hline \multirow[t]{2}{*}{$\Delta$ Negative } & -0.03 & & & 0.01 & & & -0.04 & & \\
\hline & $(0.044)$ & & & $(0.047)$ & & & $(0.045)$ & & \\
\hline \multirow[t]{2}{*}{$\Delta$ Positive } & $0.07^{*}$ & & & $0.07^{*}$ & & & $0.08^{*}$ & & \\
\hline & $(0.042)$ & & & $(0.041)$ & & & $(0.042)$ & & \\
\hline \multirow[t]{2}{*}{$\Delta$ LM Neg } & & -0.01 & & & -0.04 & & & -0.01 & \\
\hline & & $(0.038)$ & & & (0.037) & & & (0.038) & \\
\hline \multirow[t]{2}{*}{$\Delta$ LM Pos } & & 0.03 & & & 0.04 & & & 0.03 & \\
\hline & & $(0.033)$ & & & $(0.032)$ & & & $(0.033)$ & \\
\hline \multirow[t]{2}{*}{$\triangle \mathrm{NBC}$ Neg } & & & -0.02 & & & 0.06 & & & -0.02 \\
\hline & & & (0.049) & & & $(0.053)$ & & & $(0.050)$ \\
\hline \multirow[t]{2}{*}{$\triangle \mathrm{NBC}$ Pos } & & & 0.05 & & & 0.03 & & & 0.05 \\
\hline & & & (0.049) & & & (0.049) & & & $(0.050)$ \\
\hline Observations & 52,306 & 52,306 & 52,306 & 38,361 & 38,361 & 38,361 & 51,955 & 51,955 & 51,955 \\
\hline Adj. R-sq. & 0.064 & 0.064 & 0.064 & 0.003 & 0.003 & 0.003 & 0.065 & 0.065 & 0.065 \\
\hline Controls & Yes & Yes & Yes & Yes & Yes & Yes & Yes & Yes & Yes \\
\hline YQ FE & & & & & & & Yes & Yes & Yes \\
\hline Ind. FE & & & & & & & Yes & Yes & Yes \\
\hline
\end{tabular}




\title{
Table 10: Change in sentiment and future profitability
}

The table presents estimates of OLS regressions of a profitability measure. In panel A, the dependent variable is $R O A_{(t+1)}$. In panel $\mathrm{B}$, the dependent variable is $O p$. CFlow $(t+1)$. All columns include control variables similar to Table 3. Independent variables are first difference $(\Delta)$ of sentiment measures and are normalized to have mean of 0 and a standard deviation of 1 . Fixed effects are defined similar to Table 3. The coefficients of the constant, controls, and fixed effects are omitted for brevity. Standard errors are in parentheses and are clustered by firm. ***,**, and * indicate statistical significance at $1 \%, 5 \%$, and $10 \%$ levels, respectively.

Panel A

Ind. Var.

$\begin{array}{cc}\Delta \text { Negative } & -0.003^{* *} \\ & (0.001) \\ \Delta \text { Positive } & 0.004^{* * *} \\ & (0.001)\end{array}$

$\triangle \mathrm{LM}$ Neg

$\triangle$ LM Pos

$\triangle \mathrm{NBC}$ Neg

$\triangle$ NBC Pos

Obs.

Adj. R-sq.

YQ and Ind. FE

\section{Panel B}

Ind. Var.

\section{$\Delta$ Negative}

$\triangle$ Positive

$\triangle$ LM Neg

$\triangle$ LM Pos

$\triangle \mathrm{NBC}$ Neg

$\triangle$ NBC Pos

Obs.

Adj. R-sq.

YQ and Ind. FE
Dependent variable: $\mathrm{ROA}_{\mathrm{t}+1}$

(2)

(3)

(4)

(5)

(6)

$\begin{array}{ccc}-0.003 * * * & & \\ (0.001) & & \\ 0.004 * * * & & \\ (0.001) & & \\ & -0.001 & \\ & (0.001) & \\ & 0.002^{* *} & \\ & (0.001) & \\ & & -0.002 \\ & & (0.001) \\ & & 0.002^{*} \\ & & (0.001) \\ 45,792 & 45,792 & 45,792 \\ 0.640 & 0.640 & 0.640 \\ \text { Yes } & \text { Yes } & \text { Yes }\end{array}$

$-0.001$

$(0.001)$

$0.002 * *$

$(0.001)$

$-0.001$

$(0.001)$

0.002

$(0.001)$

$46,078 \quad 46,078$

0.627

0.627

46,078

0.627

Dependent variable: Op. CFlow $_{t+1}$

(1)

(2)

(3)

(4)

(5)

(6) (n)

(n)

(n)

(n)




\section{Table 11: Change in sentiment, future cash holdings, and future leverage}

The table presents estimates of OLS regressions of Cash $_{t+1}$ (panel A) and Leverage $_{t+1}$ (Panel B). All columns include control variables similar to Tables 7 and 8 . Independent variables are first difference $(\Delta)$ of sentiment measures and are normalized to have mean of 0 and a standard deviation of 1 . Fixed effects are defined similar to Tables 7 and 8 . The coefficients of the constant, controls, and fixed effects are omitted for brevity. Standard errors are in parentheses and are clustered by firm. $* * *, * *$, and * indicate statistical significance at $1 \%, 5 \%$, and $10 \%$ levels, respectively.

\begin{tabular}{|c|c|c|c|c|c|c|}
\hline Panel A & & & pendent va & able: Cash $_{t+1}$ & & \\
\hline Ind. Var. & (1) & (2) & (3) & (4) & (5) & (6) \\
\hline$\Delta$ Negative & $\begin{array}{c}0.002 * * \\
(0.001)\end{array}$ & & & $\begin{array}{c}0.002 * * \\
(0.001)\end{array}$ & & \\
\hline$\Delta$ Positive & $\begin{array}{c}-0.002 * * * \\
(0.001)\end{array}$ & & & $\begin{array}{c}-0.002 * * * \\
(0.001)\end{array}$ & & \\
\hline$\Delta \mathrm{LM}$ Neg & & $\begin{array}{c}0.001 * * \\
(0.000)\end{array}$ & & & $\begin{array}{l}0.001^{*} \\
(0.000)\end{array}$ & \\
\hline$\Delta \mathrm{LM}$ Pos & & $\begin{array}{l}-0.001 \\
(0.000)\end{array}$ & & & $\begin{array}{l}-0.001 \\
(0.000)\end{array}$ & \\
\hline$\Delta \mathrm{NBC}$ Neg & & & $\begin{array}{c}0.002 * * * \\
(0.001)\end{array}$ & & & $\begin{array}{c}0.002^{* * *} \\
(0.001)\end{array}$ \\
\hline$\triangle \mathrm{NBC}$ Pos & & & $\begin{array}{c}-0.003 * * * \\
(0.001)\end{array}$ & & & $\begin{array}{c}-0.002 * * * \\
(0.001)\end{array}$ \\
\hline Obs. & 45,393 & 45,393 & 45,393 & 45,134 & 45,134 & 45,134 \\
\hline Adj. R-sq. & 0.819 & 0.819 & 0.819 & 0.823 & 0.823 & 0.823 \\
\hline YQ and Ind. FE & & & & Yes & Yes & Yes \\
\hline $\begin{array}{l}\text { Panel B } \\
\text { VARIABLES }\end{array}$ & (1) & (2) & $\begin{array}{c}\text { ependent va } \\
\text { (3) }\end{array}$ & $\begin{array}{l}\text { iable: Levera } \\
\text { (4) }\end{array}$ & $(5)$ & (6) \\
\hline Negative & $\begin{array}{c}0.001 \\
(0.001)\end{array}$ & & & $\begin{array}{c}0.001 \\
(0.001)\end{array}$ & & \\
\hline Positive & $\begin{array}{c}-0.002 * * * \\
(0.001)\end{array}$ & & & $\begin{array}{c}-0.002 * * * \\
(0.001)\end{array}$ & & \\
\hline LM Neg & & $\begin{array}{l}-0.000 \\
(0.001)\end{array}$ & & & $\begin{array}{l}-0.000 \\
(0.001)\end{array}$ & \\
\hline LM Pos & & $\begin{array}{l}-0.000 \\
(0.001)\end{array}$ & & & $\begin{array}{l}-0.001 \\
(0.001)\end{array}$ & \\
\hline NBC Neg & & & $\begin{array}{l}-0.001 \\
(0.001)\end{array}$ & & & $\begin{array}{l}-0.001 \\
(0.001)\end{array}$ \\
\hline NBC Pos & & & $\begin{array}{c}0.000 \\
(0.001)\end{array}$ & & & $\begin{array}{l}-0.000 \\
(0.001)\end{array}$ \\
\hline Obs. & 49,228 & 49,228 & 49,228 & 48,924 & 48,924 & 48,924 \\
\hline Adj. R-sq. & 0.208 & 0.208 & 0.208 & 0.268 & 0.268 & 0.268 \\
\hline YQ and Ind. FE & & & & Yes & Yes & Yes \\
\hline
\end{tabular}




\section{Appendix A}

\section{Sentiment Classification using Deep Learning}

\section{A.1. Neural networks}

This appendix provides a brief introduction to neural networks and the method we use for sentiment classification. The left side of Figure A1 shows the basic building block of neural networks. Each input, $x_{\mathrm{i}}$, is a real number that is multiplied by a weight, $w_{\mathrm{i}}$, shown as a line connecting $x_{\mathrm{i}}$ to node $n$. The sum of the products of $x_{\mathrm{i}}$ and $w_{\mathrm{i}}, z_{\mathrm{i}}$, is the input to node $n$. The node applies a function to the input and provides a real number as the output. A logistic regression model can be represented using this structure with features as $x_{1}, x_{2}, \ldots, x_{\mathrm{n}}$, coefficients as $w_{1}, w_{2}$, $\ldots, w_{\mathrm{n}}$, and $y$ as the output of the node with function $y=1 /\left(1+e^{-z}\right)$. Nodes can be stacked up to build a layer as shown on the right side of Figure A1. The output of each node in a layer can be the input to the next layer which can be the output layer. The function that operates on the input to a node and generates the output of that node is called the activation function. Activation functions are determined before training the NN. Training neural networks refers to computing all the weights, $w_{\mathrm{i}}$, in all the layers in order to minimize a pre-defined cost (or loss) function that depends on the outputs and the weights in the NN. All the layers between the input and the output layer are called hidden layers. Deep neural networks are NN that are built using many hidden layers. NN can perform complicated tasks due to their ability to capture complex nonlinearities.

Recurrent NN (RNN) have a different structure and data flow than the feed-forward NN described above, but they have the same building blocks. Figure A2 shows a diagram of a simple RNN. $x_{t}$ is the input (which can be a vector) at time $t$ to a NN presented as a rectangle. This NN creates an output, $y_{t}$, and a state variable, $s_{t+1}$, that is used together with $x_{t+1}$ in the next time step. The NN in each time step is the same, i.e. it has the same structure with the same set of weights to be calculated during training. For the sentiment classification task in this paper, $x_{t}$ represents a word in a sentence and $y_{T}$ (where $T$ is the length of the sentence) represents a three-dimension output that shows the probability that the sentence belongs to each sentiment category. In the next section, we discuss word-embedding to find a vector representation of words, $x_{t}$, to be used in the RNN-based sentiment classifier. 


\section{A.2. Word-embedding}

Words can be represented numerically by vectors with the dimension equal to the number of words in a dictionary - the collection of all different words in the corpus under study. All elements of such a vector are zero except one which equals to 1 and corresponds to a specific word - this vector is called a one-hot vector. In this representation, only the exact same words in a text would have the same vector. While preserving the true dimensionality of words, this method has several drawbacks in practice. It does not capture any similarity between words. 'Loan' and 'Debt' are as similar or different as 'Finance' and 'Zoology'. In addition, any analysis using this word representation method requires the algorithm to have seen all the significant words in the dictionary enough times during training. Word-embedding is an NLP technique that can mitigate both concerns by finding a low-dimension (20 to 500) vector representation of words.

There are many word-embedding techniques all of which result in a low-dimension representation of words. With word-embedding, each word is represented by a continuous vector of an arbitrary dimension (200 in this paper). Mikolov et al. (2013a) propose two novel structures using neural networks to estimate word-embedding at a low computational cost with high accuracy. In another study, Mikolov et al. (2013b), further suggest some modifications to improve the quality and efficiency of word-embedding that can be performed on very large data sets. Figure A3 shows an example of a simple structure proposed by Mikolov et al. (2013a). Input is the one-hot vector of a word right before the current word in a sentence. The matrix $w_{d x N}$ (where $N$ is the number of words in the dictionary and $d$ is the word-embedding dimension) represents all the weights that connect the input vector to the hidden layer, which is the wordembedding matrix that we use once the $\mathrm{NN}$ is trained. The hidden layer is connected to the output layer which is a Softmax classifier. Each output shows the probability that the corresponding word in the dictionary is the current word. The output with the highest probability is the predicted current word. The model is trained to maximize the probability of predicting the current word correctly given the input word. We use a structure proposed by Mikolov et al. (2013a), called continuous bag-of-words (CBOW).

In a CBOW structure, given a set of neighboring words in a sentence, the probability of occurrence of the current word is maximized. Since the order of neighboring words does not 
affect the results, CBOW is a bag-of-words method. The model takes as input the average of one-hot vectors of neighboring words, instead of a single one-hot vector shown in Figure A3. The word-embedding matrix and parameters of the Softmax classifier are estimated to maximize the likelihood of predicting the current word correctly. Each column of the word-embedding matrix represents a word in the dictionary. Results of word-embedding should not be evaluated on a standalone basis, rather based on a downstream task for which it is being used. The downstream task in our study is sentiment classification discussed in the next section. Nevertheless, for illustration, we show five most similar words to 12 different financial words based on the results of our word-embedding in Table A1. Score is calculated based on the cosine similarity of the vectors corresponding to each pair of words. In general, word-embedding is known to preserve semantic and syntactic aspects of words. In a recent finance study, Li et al. (2018) use word-embedding to find a lexicon of words related to corporate culture.

\section{A.3. Sentiment classifier}

Next, we can represent each sentence as a sequence of vectors of the dimension chosen for word-embedding. We can then use $\mathrm{NN}$ and train a model to take a sentence as input and classify the sentiment in each sentence into negative, positive, and neutral. To do that, we need to have a train-set that includes manually labelled sentences and choose a NN structure and train it. We manually classify 9,500 randomly $^{25}$ selected sentences into three categories: negative, positive, and neutral. Recurrent neural network is a structure that captures the dynamics of sequential data. A specific type of RNN, long short-term memory (LSTM), proposed by Hochreiter and Schmidhuber (1997), avoids the problems of vanishing and exploding gradients when training the model. LSTM network can also learn from observations far back in the sequence, implying that it can 'memorize' words in long sentences that occurred near the beginning. We train an LSTM network (with a Softmax output layer) on the train-set of 8,000

25 We use stratified random sampling to select 9,500 sentences to assure that the data is not unbalanced, i.e. the occurrence of positive and negative sentences is not rare. Stratifies are based on LM's (2011) word lists and include 2,000 sentences chosen completely at random; 5,000 sentences that include at least one word from LM negative or positive word lists; 2,000 sentences that include at least one word from LM uncertain words; and 500 sentences that include at least one word from LM constraint words. 
sentences $^{26}$, known as the in-sample data set in the forecasting literature. The other $1,500^{27}$ sentences are then used to evaluate the out-of-sample performance of the trained model. As shown in Table 1, the accuracy of this model for in-sample and out-of-sample sentiment classification is about $91 \%$ and $90 \%$, respectively ${ }^{28}$.

The choice of the type of $\mathrm{NN}$ and the hyper-parameters ${ }^{29}$ of the model are arbitrary and researchers can evaluate the performance of different models. While the level of accuracy we achieve can potentially be improved, it is quite high in the sentiment analysis literature and significantly higher than the accuracy of the word list and NBC methods used in finance. Regarding implementation, researchers have several choices to train a NN. Tensorflow by Google, which is now open source, has a strong active community and many sample codes for machine learning tasks are available on GitHub and many weblogs. Theano is another popular choice. This paper uses Keras ${ }^{30}$, also an open source library, which requires less coding than many other choices. It is modular and user-friendly and is tailored to standard machine learning tasks that researchers in other disciplines may also find helpful.

${ }^{26}$ More precisely, we use 8,000 sentences as our train and development set to fine tune the classifier and to ensure that the classifier is not over-fitting the train-set.

${ }^{27}$ For the purpose of evaluation, the appropriate size of the out-of-sample set is $10 \%$ to $20 \%$ of the size of in-sample train-set.

${ }^{28}$ Note that in Table 2, the percentage of positive sentences is relatively small. This is due to the nature of the textual data we use, i.e. 10-K filings.

${ }^{29}$ Some examples of hyper-parameters are the number of hidden layers, the number of nodes in each layer, the dimension of word-embedding, the method of training and its parameters.

${ }^{30}$ We use Python in all steps, i.e. preprocessing 10-K filings, performing word-embedding, and training the sentiment classifier. All the packages mentioned in the paper can be imported and used in Python. 


\section{Figure A1}

The figure on the left shows the building block of neural networks (NN). The inputs are $x_{1}, x_{2}, \ldots, x_{i}$, which are real numbers. Solid lines represent weights, and $y$ is the output of node $n$ which is a function of $\sum x_{i} . w_{i}$. The figure on the right shows a simple $\mathrm{NN}$ with 2 hidden layers. All inputs are connected to all nodes in layer $1 ; y$ is the output of the NN.
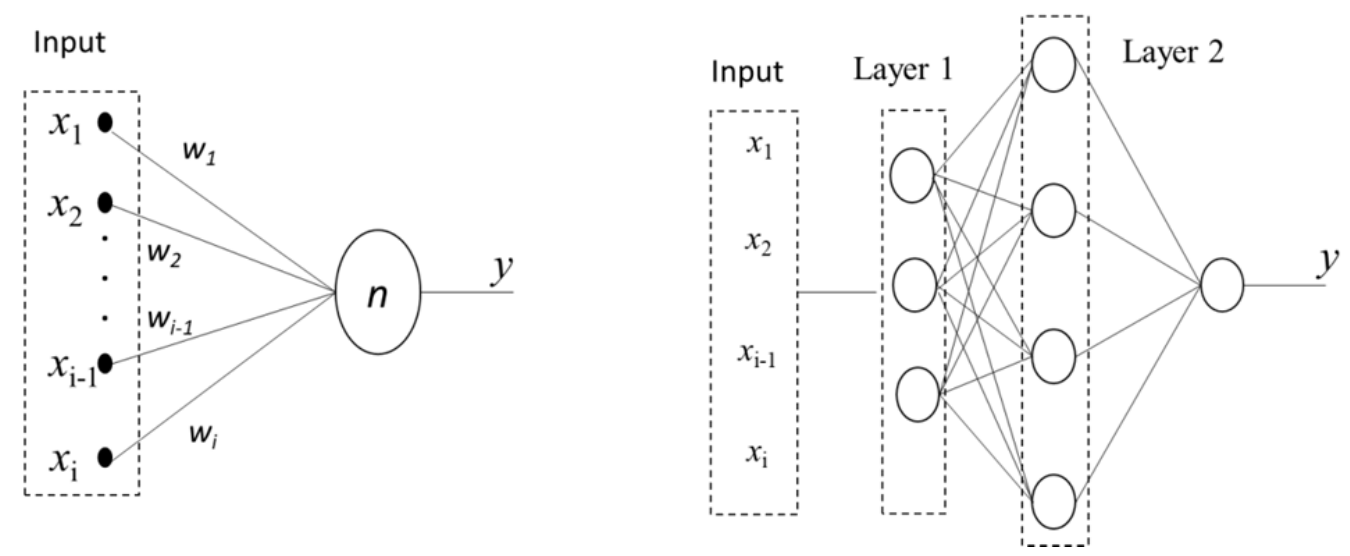

\section{Figure A2}

This figure shows the structure and data flow of a simple recurrent neural network (RNN). The input is $x_{t}$ which has a time stamp, and the output is $y_{t}$. The building blocks are the same at all time steps. The state variable $s_{t}$ carries forward the information from time $t-1$ to time $t$.

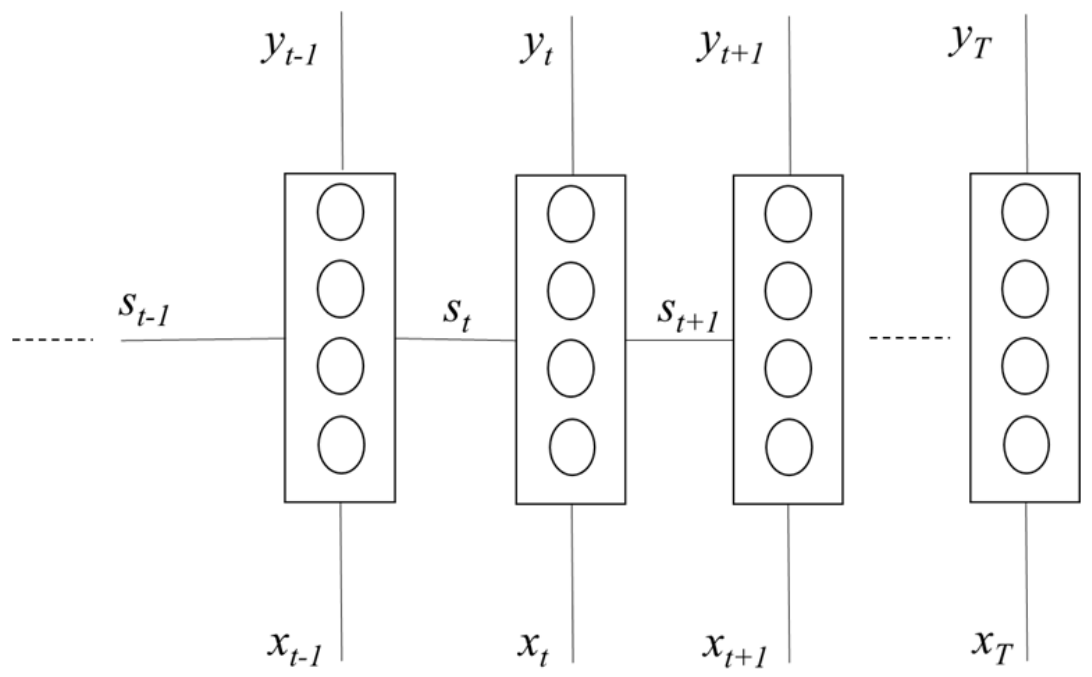




\section{Figure A3}

A simple structure to perform word-embedding using neural networks $(\mathrm{NN})$ proposed by Mikolov et. al. (2013a). The input is the one-hot vector associated with a neighboring word to the current word. Each output represents the probability that the $\mathrm{NN}$ assigns to that word being the target word based on the input word. The word-embedding matrix is associated with the weights that connect the input vector to the hidden layer, $d$ is the dimension of word-embedding, and $N$ is the number of words in the dictionary.

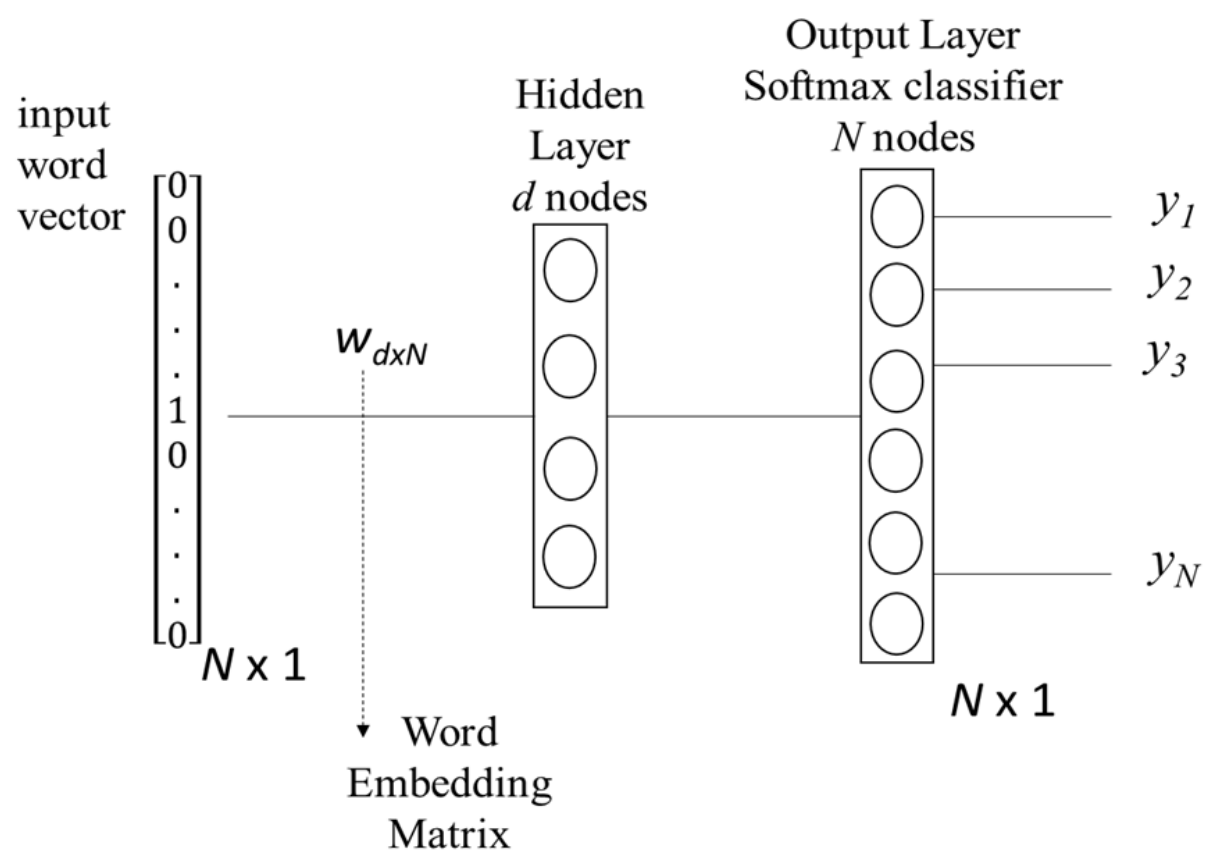




\section{Table A1}

The table shows the five most similar words to 12 selected words based on the results of wordembedding. Score is cosine similarity. Each word is associated with a vector of dimension 200 calculated in the word-embedding stage. Score is calculated using the cosine similarity function. (If $\mathrm{v}_{1}$ and $\mathrm{v}_{2}$ are two word vectors, cosine similarity is calculated as $\left(\mathrm{v}_{1} \cdot \mathrm{v}_{2}\right) /\left\|\mathrm{v}_{1}\right\| \cdot\left\|\mathrm{v}_{2}\right\|$, where the numerator is the inner product of the two vectors and $\|$.$\| represents geometric magnitude.)$

\begin{tabular}{|c|c|c|c|c|c|c|}
\hline Word & penalties & Score & competition & Score & operations & Score \\
\hline \multirow{5}{*}{$\begin{array}{c}\text { Most } \\
\text { Similar }\end{array}$} & fines & 0.72 & intense & 0.80 & results & 0.70 \\
\hline & penalty & 0.68 & competitive & 0.75 & operating & 0.64 \\
\hline & criminal & 0.64 & compete & 0.73 & business & 0.58 \\
\hline & civil & 0.61 & competing & 0.72 & condition & 0.58 \\
\hline & underpayment & 0.55 & competitors & 0.66 & profitability & 0.57 \\
\hline
\end{tabular}

\begin{tabular}{|c|lc|lc|lc|}
\hline Word & skilled & Score & profit & Score & mercedes & Score \\
\hline \multirow{5}{*}{ Most } & talented & 0.68 & margins & 0.70 & volvo & 0.70 \\
Similar & nurses & 0.67 & gross & 0.70 & chevrolet & 0.69 \\
& personnel & 0.66 & margin & 0.63 & toyota & 0.68 \\
& trained & 0.66 & profits & 0.63 & mazda & 0.67 \\
& professionals & 0.65 & revenues & 0.62 & lexus & 0.67 \\
\hline Word & risk & & & & & Score \\
\hline \multirow{5}{*}{ Most } & Score & loss & Score & loan & 0.81 \\
Similar & exposure & 0.74 & losses & 0.72 & loans & 0.71 \\
& exposed & 0.64 & gain & 0.62 & mortgage & 0.68 \\
& exposures & 0.63 & net & 0.57 & credit & 0.61 \\
& sensitivity & 0.63 & income & 0.57 & lender & 0.60 \\
\hline
\end{tabular}

\begin{tabular}{|c|lc|lc|lc|}
\hline Word & innovation & Score & patent & Score & research & Score \\
\hline \multirow{5}{*}{ Most } & innovative & 0.72 & patents & 0.91 & development & 0.76 \\
& excellence & 0.70 & uspto & 0.76 & collaborative & 0.60 \\
& innovations & 0.66 & trademark & 0.74 & commercialization & 0.60 \\
& innovate & 0.61 & intellectual & 0.74 & crada & 0.59 \\
& creativity & 0.61 & infringement & 0.67 & preclinical & 0.59 \\
\hline
\end{tabular}




\section{Table A2}

This table presents several sentences classified under our approach as negative (positive) or neutral, and the positive (negative) words in them based on the Loughran and McDonald (2011) word lists.

\begin{tabular}{|c|c|}
\hline Positive Words & Negative Sentence \\
\hline $\begin{array}{l}\text { achieve, greater, } \\
\text { gain }\end{array}$ & $\begin{array}{l}\text { For these and other reasons, these competitors may achieve greater acceptance in the } \\
\text { marketplace than our company, limiting our ability to gain market share and customer } \\
\text { loyalty and increase our revenues. }\end{array}$ \\
\hline $\begin{array}{l}\text { greater, better, } \\
\text { able }\end{array}$ & $\begin{array}{l}\text { Furthermore, competitors who have greater financial resources may be better able to } \\
\text { provide a broader range of financing alternatives to their customers in connection with } \\
\text { sales of their products. }\end{array}$ \\
\hline $\begin{array}{l}\text { enjoy, } \\
\text { advantages, } \\
\text { greater }\end{array}$ & $\begin{array}{l}\text { Many of these potential competitors are likely to enjoy substantial competitive } \\
\text { advantages, including greater resources that can be devoted to the development, } \\
\text { promotion and sale of their products. }\end{array}$ \\
\hline $\begin{array}{l}\text { successful, } \\
\text { alliances, able }\end{array}$ & $\begin{array}{l}\text { There can be no assurance that we will be successful in our ongoing strategic alliances or } \\
\text { that we will be able to find further suitable business relationships as we develop new } \\
\text { products and strategies. }\end{array}$ \\
\hline $\begin{array}{l}\text { successful, able, } \\
\text { achieve, } \\
\text { profitability }\end{array}$ & $\begin{array}{l}\text { There can be no assurance that any of the Company's business strategies will be } \\
\text { successful or that the Company will be able to achieve profitability on a quarterly or } \\
\text { annual basis. }\end{array}$ \\
\hline $\begin{array}{l}\text { able, } \\
\text { opportunities, } \\
\text { opportunities, } \\
\text { favorable }\end{array}$ & $\begin{array}{l}\text { We cannot assure you that we will be able to identify suitable acquisition or joint venture } \\
\text { opportunities in the future or that any such opportunities, if identified, will be } \\
\text { consummated on favorable terms, if at all. }\end{array}$ \\
\hline $\begin{array}{l}\text { successfully, } \\
\text { enhance, } \\
\text { advantage, } \\
\text { opportunities }\end{array}$ & $\begin{array}{l}\text { If additional financing is not available when required or is not available on acceptable } \\
\text { terms, we may be unable to fund our expansion, successfully promote our brand name, } \\
\text { develop or enhance our products and services, take advantage of business opportunities, } \\
\text { or respond to competitive pressures, any of which could have a material adverse effect on } \\
\text { our business. }\end{array}$ \\
\hline $\begin{array}{l}\text { collaborative, } \\
\text { achieve, } \\
\text { profitability }\end{array}$ & $\begin{array}{l}\text { Our long-term liquidity also depends upon our ability to attract and maintain collaborative } \\
\text { relationships, to increase revenues from the sale of our products, to develop and market } \\
\text { new products and ultimately, to achieve profitability. }\end{array}$ \\
\hline $\begin{array}{l}\text { able, success, } \\
\text { able, achieve }\end{array}$ & $\begin{array}{l}\text { Even if we are able to develop new products, the success of each new product depends on } \\
\text { several factors including whether we selected the proper product and our ability to } \\
\text { introduce it at the right time, whether the product is able to achieve acceptable production } \\
\text { yields and whether the market accepts the new product. }\end{array}$ \\
\hline $\begin{array}{l}\text { efficiencies, } \\
\text { benefit, achieved }\end{array}$ & $\begin{array}{l}\text { Although Stratos expects that the elimination of duplicative costs, as well as the } \\
\text { realization of other efficiencies related to the integration of the businesses, may offset } \\
\text { incremental transaction, merger-related and restructuring costs over time, we cannot give } \\
\text { any assurance that this net benefit will be achieved in the near term, or at all. }\end{array}$ \\
\hline
\end{tabular}




\section{Table A2 (cont.)}

\begin{tabular}{|l|l|}
\hline Positive words & Neutral Sentence \\
\hline $\begin{array}{l}\text { gain, greater, } \\
\text { gain }\end{array}$ & $\begin{array}{l}\text { If a business combination results in a bargain purchase for us, the economic gain resulting } \\
\text { from the fair value received being greater than the purchase price is recorded as a gain } \\
\text { included in other income (expense), net, in the Consolidated Statements of } \\
\text { Comprehensive Loss. }\end{array}$ \\
\hline $\begin{array}{l}\text { improvements, } \\
\text { improvements, } \\
\text { improvements }\end{array}$ & $\begin{array}{l}\text { The estimated lives used in determining depreciation and amortization are: Buildings and } \\
\text { improvements 12-40 years, Warehouse and office equipment 5-7 years, and Automobiles } \\
3-5 \text { years. Leasehold improvements are amortized over the lives of the respective leases or } \\
\text { the service lives of the improvements, whichever is shorter. }\end{array}$ \\
\hline $\begin{array}{l}\text { superior, } \\
\text { opportunity, } \\
\text { superior }\end{array}$ & $\begin{array}{l}\text { If the Company receives a Superior Proposal, Parent must be given the opportunity to } \\
\text { match the Superior Proposal. }\end{array}$ \\
\hline $\begin{array}{l}\text { enables, } \\
\text { exceptional, } \\
\text { strength }\end{array}$ & $\begin{array}{l}\text { Specialty steels are made with a high alloy content, which enables their use in } \\
\text { environments that demand exceptional hardness, toughness, strength and resistance to } \\
\text { heat, corrosion or abrasion, or combinations thereof. }\end{array}$ \\
\hline $\begin{array}{l}\text { greater, greater, } \\
\text { advances }\end{array}$ & $\begin{array}{l}\text { Majority Lenders means Lenders having greater than 50\% of the total Commitments or, if } \\
\text { the Commitments have been terminated in full, Lenders holding greater than 50\% of the } \\
\text { then aggregate unpaid principal amount of the Advances. }\end{array}$ \\
\hline
\end{tabular}

\begin{tabular}{|l|l|}
\hline Negative Words & Positive Sentence \\
\hline $\begin{array}{l}\text { disputes, } \\
\text { difficulty }\end{array}$ & $\begin{array}{l}\text { We believe that we maintain a satisfactory working relationship with our employees, and } \\
\text { we have not experienced any significant labor disputes or any difficulty in recruiting staff } \\
\text { for our operations. }\end{array}$ \\
\hline $\begin{array}{l}\text { serious, adverse, } \\
\text { unexpected, } \\
\text { irreversible }\end{array}$ & $\begin{array}{l}\text { No serious adverse events and no unexpected or irreversible side effects were reported in } \\
\text { the Ceplene study. }\end{array}$ \\
\hline Problems & $\begin{array}{l}\text { We also maintain a separate technical support group dedicated to answering specific } \\
\text { customer inquiries and assisting customers with the operation of products and finding low } \\
\text { cost solutions to manufacturing problems. }\end{array}$ \\
\hline Bad & In 2003, we reduced bad debt expense by \$0.4 million versus 2002. \\
\hline Unable & $\begin{array}{l}\text { We believe the effect of this law will be to accelerate sales of our needleless systems, } \\
\text { although we are unable to estimate the amount or timing of such sales. }\end{array}$ \\
\hline claims, against & These agreements released all legal claims against us. \\
\hline $\begin{array}{l}\text { dismissing, } \\
\text { claims, against }\end{array}$ & $\begin{array}{l}\text { On November 28, 2012, the Federal Court in the MDL entered an order dismissing all } \\
\text { claims against Nalco. }\end{array}$ \\
\hline against, damage & $\begin{array}{l}\text { Lower Lakes maintains insurance on its fleet for risks commonly insured against by vessel } \\
\text { owners and operators, including hull and machinery insurance, war risks insurance and } \\
\text { protection and indemnity insurance (which includes environmental damage and pollution } \\
\text { insurance). }\end{array}$ \\
\hline $\begin{array}{l}\text { Susceptible } \\
\text { loss, } \\
\text { interruption }\end{array}$ & $\begin{array}{l}\text { Management believes that the Company's container manufacturing capabilities makes the } \\
\text { Company less susceptible than its competitors to ocean-going container price fluctuations, } \\
\text { particularly since the cost of used containers is affected by many factors, only one of } \\
\text { which is the cost of steel from which the Company can manufacture new containers. }\end{array}$ \\
$\begin{array}{l}\text { We also maintain coverage for property damage or loss, general liability, business } \\
\text { interruption, travel-accident, directors and officers liability and workers compensation. }\end{array}$ \\
\hline
\end{tabular}


Table A2 (cont.)

\begin{tabular}{|l|l|}
\hline Negative Words & Neutral Sentences \\
\hline $\begin{array}{l}\text { loss, impairment, } \\
\text { loss, loss }\end{array}$ & $\begin{array}{l}\text { We consider the likelihood of loss or impairment of an asset or the incurrence of a } \\
\text { liability, as well as our ability to reasonably estimate the amount of loss in determining } \\
\text { loss contingencies. }\end{array}$ \\
\hline $\begin{array}{l}\text { critical, critical, } \\
\text { doubtful, } \\
\text { restructuring }\end{array}$ & $\begin{array}{l}\text { Our critical accounting policies are as follows: revenue recognition; allowance for } \\
\text { doubtful accounts; accounting for income taxes; and restructuring charge. }\end{array}$ \\
\hline $\begin{array}{l}\text { impairment, } \\
\text { impairment, } \\
\text { impairment, loss }\end{array}$ & $\begin{array}{l}\text { If it is more likely than not that a goodwill impairment exists, the second step of the } \\
\text { goodwill impairment test must be performed to measure the amount of the goodwill } \\
\text { impairment loss, if any. }\end{array}$ \\
\hline $\begin{array}{l}\text { impairment, loss, } \\
\text { impairment, } \\
\text { impairment }\end{array}$ & $\begin{array}{l}\text { Unproved oil and gas properties that are individually significant are periodically assessed } \\
\text { for impairment of value, and a loss is recognized at the time of impairment by providing } \\
\text { an impairment allowance. }\end{array}$ \\
\hline $\begin{array}{l}\text { disclose, loss, } \\
\text { litigation, claims }\end{array}$ & $\begin{array}{l}\text { We account for and disclose loss contingencies such as pending litigation and actual or } \\
\text { possible claims and assessments in accordance with the FASB s authoritative guidance on } \\
\text { accounting for contingencies. }\end{array}$ \\
\hline
\end{tabular}




\section{Appendix B: Variable Definitions}

\begin{tabular}{|c|c|}
\hline Negative & $\begin{array}{l}\text { Ratio of the number of negative sentences based on our deep learning approach to } \\
\text { the total number of sentences in a } 10-\mathrm{K} \text { filing }\end{array}$ \\
\hline Positive & $\begin{array}{l}\text { Ratio of the number of positive sentences based on our deep learning approach to } \\
\text { the total number of sentences in a } 10-\mathrm{K} \text { filing }\end{array}$ \\
\hline LM Neg & $\begin{array}{l}\text { Ratio of the number of negative words based on Loughran and McDonald's } \\
\text { (2011) negative word list to the total number of words in a } 10-\mathrm{K} \text { filing. Positive } \\
\text { words preceded within the last three words by no, not, none, neither, never, } \\
\text { nobody\} are considered negative }\end{array}$ \\
\hline LM Pos & $\begin{array}{l}\text { Ratio of the number of positive words based on Loughran and McDonald's } \\
\text { (2011) positive word list to the total number of words in a 10-K filing. Positive } \\
\text { words preceded within the last three words by no, not, none, neither, never, } \\
\text { nobody\} are considered negative }\end{array}$ \\
\hline NBC Neg & $\begin{array}{l}\text { Ratio of the number of negative sentences based on Naïve Bayes classifier to the } \\
\text { total number of sentences in a } 10-\mathrm{K} \text { filing }\end{array}$ \\
\hline NBC Pos & $\begin{array}{l}\text { Ratio of the number of positive sentences based on Naïve Bayes classifier to the } \\
\text { total number of sentences in a } 10-\mathrm{K} \text { filing }\end{array}$ \\
\hline Abnormal Volume & $\begin{array}{l}\text { The average trading volume over the 4-day event window }[0,+3] \text {, where volume } \\
\text { is standardized based on its mean and standard deviation over days }[-65,-6] \\
\text { before the } 10-\mathrm{K} \text { filing date }\end{array}$ \\
\hline$B / M$ & Book value of common equity divided by market value of common equity \\
\hline $\operatorname{CAR}(0,+3)$ & $\begin{array}{l}\text { Cumulative abnormal return over days }[0,+3] \text { using the three Fama and French } \\
\text { factors and momentum }\end{array}$ \\
\hline Cash & Cash and cash equivalents divided by total assets, che / at \\
\hline EARet & 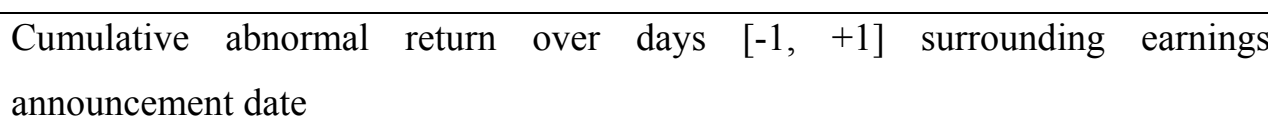 \\
\hline Leverage & $\begin{array}{l}\text { Leverage ratio, measured as (long-term debt plus debt in current liabilities) } \\
\text { divided by total assets, }(l d t t+d l c) / a t\end{array}$ \\
\hline Log(Sale) & Natural log of total sales, $\ln ($ sale $)$ \\
\hline Market Cap. & Natural log of market value of common shares, $\ln \left(\operatorname{prcc} \_f^{*}\right.$ csho $)$ \\
\hline Op. CFlow & Cash flow from operating activities divided by lagged total assets, oancf $/ a t_{(t-1)}$ \\
\hline$R O A$ & Operating income before depreciation divided by lagged total assets, $\operatorname{oibdp}_{t} / a t_{(t-1)}$ \\
\hline ROA Vol. & Standard deviation of ROA over the last 5 years \\
\hline
\end{tabular}




\begin{tabular}{|l|l|}
\hline Ret. Vol. & Standard deviation of monthly returns over the last 12 months \\
\hline$R \& D$ & Research and development expenses divided by lagged total assets, $x \mathrm{rd}_{t} / \mathrm{at}_{(t-1)}$ \\
\hline Sales Growth & Sales growth over the last year $\left(\right.$ Sale $_{t}-$ Sale $\left._{t-1}\right) /$ Sale $_{t-1}$ \\
\hline Tangibility & Property, plant, and equipment divided by total assets ppent/at \\
\hline Tobin's $Q$ & $\left(\left(\right.\right.$ prcc_f ${ }^{*}$ csho $\left.)+p s t k+d l t t+d l c\right) / a t$ \\
\hline Total Assets & Natural log of total assets, $\ln ($ at $)$ \\
\hline
\end{tabular}

